\title{
Phase evolution of vanadium oxides obtained through temperature programmed calcinations of ammonium vanadate in hydrogen atmosphere and their humidity sensing properties
}

A. A. Akande ${ }^{1,2}$, E. C. Linganiso ${ }^{1}$, B. P. Dhonge ${ }^{1}$, K. E. Rammutla ${ }^{2}$, A. Machatine ${ }^{3}$, L. Prinsloo $^{3}$, H. Kunert ${ }^{3}$, B. W. Mwakikunga ${ }^{1, *}$

${ }^{1}$ DST/CSIR National Centre for Nano-Structured Materials, P O Box 395, Pretoria 0001, South Africa

${ }^{2}$ University of Limpopo, Department of Physics, P/Bag X1106, Sovenga, 0727, RSA

${ }^{3}$ School of Physics, University of Pretoria, Pretoria, 0002, South Africa

\section{Abstract}

The possibility of obtaining vanadium dioxide $\left(\mathrm{VO}_{2}\right)$ [wherein the vanadium ionic state is $4^{+}$] from a precursor of ammonium metavanadate $\left(\mathrm{NH}_{4} \mathrm{VO}_{3}\right)$ bearing the ion $\mathrm{V}^{5+}$ is investigated. The reduction is carried out by calcining the $\mathrm{NH}_{4} \mathrm{VO}_{3}$ powders in similar concentrations of $\mathrm{H}_{2}$ flow at varying temperatures. The resulting powders have been studied by several techniques including XRD, Raman spectroscopy, FTIR, TEM, BET and DSC. It is found that remnants of bright yellow $\mathrm{V}^{5+}$ still exist up to calcination temperatures of $100{ }^{0} \mathrm{C}$ after which the sky-blue $\mathrm{VO}_{2}$ dominates at calcination temperatures of $150{ }^{0} \mathrm{C}$ to $250{ }^{0} \mathrm{C}$. There is a population surge of metastable dark-blue $\mathrm{V}_{6} \mathrm{O}_{13}$ (where $\mathrm{V}$ is in between $\mathrm{V}^{4+}$ and $\mathrm{V}^{5+}$ ionic states) between $250{ }^{\circ} \mathrm{C}$ and $300{ }^{\circ} \mathrm{C}$. However above $350{ }^{\circ} \mathrm{C}$ the material reverts to the stable

\footnotetext{
* Author to whom correspondence is to be addressed: Bonex Mwakikunga Email address: bmwakikunga@csir.co.za Fax: +27 128412229
} 
$\mathrm{V}^{5+}$ in the yellow-orange $\mathrm{V}_{2} \mathrm{O}_{5}$. XPS/EDS and VSM confirm the order of appearance to be $\mathrm{VO}_{2}\left(150^{\circ} \mathrm{C}\right) \rightarrow \mathrm{V}_{6} \mathrm{O}_{13}\left(200^{\circ} \mathrm{C}\right) \rightarrow \mathrm{V}_{2} \mathrm{O}_{5}\left(350^{\circ} \mathrm{C}\right)$.

\section{Introduction}

An oxidation state is influenced by ionization energy while ionization energy depends on the shielding effect between the orbital electron and the nucleus of an atom. In transition metal elements, the electrons enter an inner-shell electron orbital as opposed to other groups where electrons enter the outer-shell electron orbital [1]. The substitution of electrons in the inner-shell in case of transition metals consequently increases the shielding effect, decreases the effective nuclear charge and thereby weakening the ionization energy. All transition metals (Ti, W, Mn, V, Cr, Pd, Pt, Co, Zn, Fe, Cd, Cu, etc.) have low ionization energy, and this makes it less costly to remove more than one electron from their orbitals than it is from compounds with completely filled $3 \mathrm{~s}$ or $3 \mathrm{~d}$ orbitals such as alkali metals and alkali earth metal elements. Vanadium is one of these transition metals, it usually presents synthesis difficulties due to its existence in several oxidation states by forming a variety of binary oxides with the following general formulas for $\mathrm{n}=1,2,3 \ldots$ (1) $\mathrm{V}_{\mathrm{n}} \mathrm{O}_{2 \mathrm{n}+1}$ e.g. $\mathrm{V}_{2} \mathrm{O}_{5}, \mathrm{~V}_{3} \mathrm{O}_{7}$, $\mathrm{V}_{4} \mathrm{O}_{9}, \mathrm{~V}_{6} \mathrm{O}_{13}$, (2) $\mathrm{V}_{\mathrm{n}} \mathrm{O}_{2 \mathrm{n}-1}$ e.g. $\mathrm{VO}, \mathrm{V}_{2} \mathrm{O}_{3}$, and (3) $\mathrm{V}_{\mathrm{n}} \mathrm{O}_{2 \mathrm{n}}$ also with $\mathrm{VO}_{2}$ and $\mathrm{V}_{2} \mathrm{O}_{4}$ [2]. Among these oxides, $\mathrm{V}_{2} \mathrm{O}_{3}, \mathrm{VO}_{2}, \mathrm{~V}_{6} \mathrm{O}_{13}$ and $\mathrm{V}_{2} \mathrm{O}_{5}$ possess many interesting characteristics that can be used in various applications because of their tendency to undergo metal to insulator phase transition commonly known as MIT transition [3-12].

Vanadium dioxide $\left(\mathrm{VO}_{2}\right)$ is unique among these oxides because of the abrupt changes in its crystal structure that usually follow the phase transition around $68{ }^{0} \mathrm{C}$. The transition temperature is considerably low and close to room temperature. This MIT property was first observed by F.J. Morin 1959 and later widely studied by Magneli, Mott Hubbard, Peirels, 
Goodenough, Adlar, Paquet and Fujimori [3-12]. $\mathrm{VO}_{2}$ has $4^{+}$oxidation state oxide of vanadium with a monoclinic (insulating/semiconducting) before transition temperature and tetragonal (metallic) above the transition temperature. Changes in crystal structure explained by Peierls as electron-phonon interaction or coupling, or band structure shift explained by Mott as electron-electron correlation is usually accompanied by a number of physical properties [13]. Such properties are changes in electrical resistance or conductance, optical transmittance or reflectance, phonon frequencies from Raman spectroscopy and FTIR, surface plasmon resonance from absorption spectra and light scattering studies [14, 17-21]. The optical property of $\mathrm{VO}_{2}$ is also found to be dependent on the surface roughness by AFM studies [15-16]. All these properties make $\mathrm{VO}_{2}$ feasible for practical application purposes and have been applied in various technological devices. Such devices include smart or switchable window glass panes (thermo-chromic and photo-chromic property) [22-26] as well as gas chemical sensing (gaso-chromic property) [22, 27]. Uses of $\mathrm{VO}_{2}$ in the fabrication of electrochemical devices (electro-chromic property) have also been recorded [28].

Other oxides such as $\mathrm{V}_{6} \mathrm{O}_{13}$ and vanadium pentoxide $\left(\mathrm{V}_{2} \mathrm{O}_{5}\right)$ are also relevant as they are close to $\mathrm{VO}_{2}$ in stoichiometry. $\mathrm{V}_{2} \mathrm{O}_{5}$ is a $\mathrm{V}^{5+}$ oxidation state oxide and is the most stable oxide of vanadium. Its orthorhombic crystal structure usually undergoes metal to insulator phase transition at $375{ }^{0} \mathrm{C} . \mathrm{V}_{2} \mathrm{O}_{5}$ is used as a passive electrode with $\mathrm{WO}_{3}$ as an active electrode in electro-chromic glass application [28-29]. It has been reported for gas chemical sensing capabilities [30] and also found applications in the lithium ion batteries [31]. $\mathrm{V}_{6} \mathrm{O}_{13}$ is known as a mixed valence oxide as it exists between the $\mathrm{V}^{4+}$ and $\mathrm{V}^{5+}$ oxidation states. [32]. It is monoclinic in crystal structure at both high and low temperature with a characteristic zigzag chain running along the $\mathrm{b}$-axis with mono $\mathrm{V}^{4+}$ and mixed $\mathrm{V}^{4+}$ and $\mathrm{V}^{5+}$ [32]. Its transition temperature is $-143{ }^{\circ} \mathrm{C}$ and finds application in lithium ion batteries. 
Ammonium meta-vanadate $\left(\mathrm{AMV}, \mathrm{NH}_{4} \mathrm{VO}_{3}\right)$ has been widely used as a source material for the syntheses of vanadium oxides by various deposition/synthesis techniques, such as chemical precipitation [33, 34], thermal annealing [35], spray pyrolysis [36, 37], and autoclave hydrothermal treatment [38].

In all these synthesis techniques, the phase diagram of V-O system was not followed. As a result, many such reports indicated either single phase $\mathrm{VO}_{2}$ or $\mathrm{V}_{2} \mathrm{O}_{5}$ without validation. In this work, we started by thermogravimetry of $\mathrm{NH}_{4} \mathrm{VO}_{3}$ in nitrogen. Instead of mass loss alone, we also observed mass increase. This prompted further systematic study of phases at various temperatures in hydrogen atmosphere. This paper reports the quantitative study of phases of $\mathrm{VO}_{\mathrm{x}}$ at various temperatures. This study sheds more light on the existing phase diagrams of $\mathrm{VO}_{\mathrm{x}}$.

\section{Experimental techniques}

Ammonium metavanadate powder $\left(\mathrm{NH}_{4} \mathrm{VO}_{3}\right.$, purity 99.99\%, molecular weight of 116 . 98 a.m.u, density of $2.3 \mathrm{~g} \mathrm{~cm}^{-1}$ and melting (or decomposition) temperature of $200{ }^{0} \mathrm{C}$ ) was purchased from Sigma-Aldrich Chemical Co. Differential scanning calorimetry (DSC) analysis was performed on the powder using DSC Q2000 V24.4 Build 116 to measure the amount of heat flow into and out of the sample relative to the reference pan with a linear temperature ramp under nitrogen gas. A series of heat treatments were performed for better understanding of the decomposition and phase change in the material. Firstly, heat treatment of the $\mathrm{NH}_{4} \mathrm{VO}_{3}$ powder was carried out for 400 and $500{ }^{0} \mathrm{C}$ in chemical vapour deposition (CVD) reactor under nitrogen flow. This experiment was followed by the TGA measurement of the resulting powder $(5.096 \mathrm{mg})$ and that of standard $\mathrm{NH}_{4} \mathrm{VO}_{3}(4.726 \mathrm{mg})$ to study the thermal decomposition process in the materials under nitrogen atmosphere. The instrument used is TGA Q500 V20.10 Build 36 by Anton Paar Inc. Further a comprehensive CVD 
calcinations of $\mathrm{NH}_{4} \mathrm{VO}_{3}$ powder under $20 \mathrm{~mL} \mathrm{~min}^{-1}$ hydrogen flow was performed in two different sections, firstly at 100, 150, 200 and secondly at 250,300 , and $350{ }^{\circ} \mathrm{C}$ for 2 hours.

The powder was characterized using an X-Ray diffraction (Panalytical X' pert Pro PW 3040/60 XRD equipped with $\mathrm{Cu} \mathrm{K} \alpha(\lambda=0.154 \mathrm{~nm})$ monochromatic radiation source). XRD patterns were recorded in the scanning range of $5-90^{0}$. DSC of these calcined powders was also studied. Raman spectroscopic studies were conducted using a Jobin-Yvon T64000 Raman spectrograph with a $514.5 \mathrm{~nm}$ excitation wavelength from an argon ion laser. The power of the laser at the sample was low enough $(0.384 \mathrm{~mW})$ in order to minimise localised heating of the sample. The T64000 was operated in a single spectrograph mode, with the 1800 lines/mm grating and a 100x objective on the microscope, and further optical measurements were performed with standard spectrum 100 PerkinElmer FT-IR spectrometer. The microscopic studies and quantitative elemental composition studies were carried out using JEOL 2100 Transmission Electron Microscopy (TEM) (from Tokyo Japan) equipped with LaB6 filament and a Gartan U1000 camera of 2028 X 2028 pixels, and high quality inbuilt Energy dispersive X-ray spectroscopy (EDS).

X-ray photo-electron spectroscopy (XPS) was also performed on a reference sample containing $\mathrm{V}_{2} \mathrm{O}_{5}, \mathrm{VO}_{2}, \mathrm{~V}_{6} \mathrm{O}_{13}$ as well domains of $\mathrm{WO}_{3}$. EDS taken from $\mathrm{VOx}$ domains (excluding the WO3 domains) in HRTEM was also performed on the same reference sample. The XPS determinations of the proportion of $\mathrm{V}^{3+}, \mathrm{V}^{4+}$ and $\mathrm{V}^{5+}$ were used to calibrate the EDS spectra and this information was then employed in the determination of the proportions of $\mathrm{V}^{3+}$,

$\mathrm{V}^{4+}$ and $\mathrm{V}^{5+}$ for the current set of samples. X-ray photoelectron spectroscopy analyses were carried using a PHI 5000 Versaprobe- Scanning ESCA Microprobe. The survey scans were recorded with a $100 \mu \mathrm{m}, 25 \mathrm{~W}, 15 \mathrm{kV}$ beam using monochromatic $\mathrm{Al} \mathrm{K}_{\alpha}$ radiation $(\mathrm{h} v=$ $1486.6 \mathrm{eV}$ ) and for the higher resolution spectra the hemispherical analyzer pass energy was maintained at $514 \mathrm{eV}$ to $520 \mathrm{eV}(\mathrm{C} 1 \mathrm{~s}, \mathrm{O} 1 \mathrm{~s}, \mathrm{~V} 2 \mathrm{p})$ for 50 cycles. Measurements were 
performed using either a $1 \mathrm{eV} / \mathrm{step}$ and $45 \mathrm{~min}$ acquisition time (binding energies ranging from 0 to $1000 \mathrm{eV}$ ) for survey scans or a $0.1 \mathrm{eV} / \mathrm{step}$ and 20-30 min acquisition times for the high-resolution scans. The pressure during acquisition was typically under $1 \times 10-8$ Torr. The surfaces were also sputtered clean for $30 \mathrm{~s}$ using an Ar ion gun ( $2 \mathrm{kV}$ energy ions) and measurements were repeated.

The field dependent magnetic characterization was performed using Lakeshore 735 vibrating sample magnetometer (VSM) at room temperature. It is vital to point out that because this type of sample exhibits small magnetization signals, special care was taken during measurements as to avoid any trace magnetic contamination. Magnetic measurements performed on the different batches of $\mathrm{VO}_{\mathrm{x}}$ powders showed consistent and reproducible results demonstrating paramagnetic behaviour.

Gas sensing properties were obtained by placing the $\mathrm{VO}_{\mathrm{x}}$ paste dispersed in ethanol onto inter-digitated electrodes and obtaining controlled transient readings of current in varying levels of analyte. The measurements were accomplished by employing a Kinosistec (Italy) gas sensor test instrument comprising Keithley voltage and current sources as well as source meters.

\section{Results and Discussions}

\subsection{Thermal Analysis (DSC/TGA)}

Fig. 1 (a) shows the DSC profile of $\mathrm{NH}_{4} \mathrm{VO}_{3}$ recorded in the temperature range of -47 ${ }^{0} \mathrm{C}$ to $350{ }^{0} \mathrm{C}$ and exothermic enthalpy change reaction of about $-38.3 \mathrm{~mW}$ was observed around $234{ }^{0} \mathrm{C}$ which may be due to the decomposition of the material. The other enthalpy change at the $340{ }^{0} \mathrm{C}$ is small and may be due to the formation of $\mathrm{V}_{2} \mathrm{O}_{5}$ phase as it occurred at a temperature close to its phase transition temperature $\left(375{ }^{0} \mathrm{C}\right)$. Fig. 1 (b) shows TGA/DTA profile of $\mathrm{NH}_{4} \mathrm{VO}_{3}$ recorded in the temperature range of $26-900{ }^{0} \mathrm{C}$. The thermogravimetry 

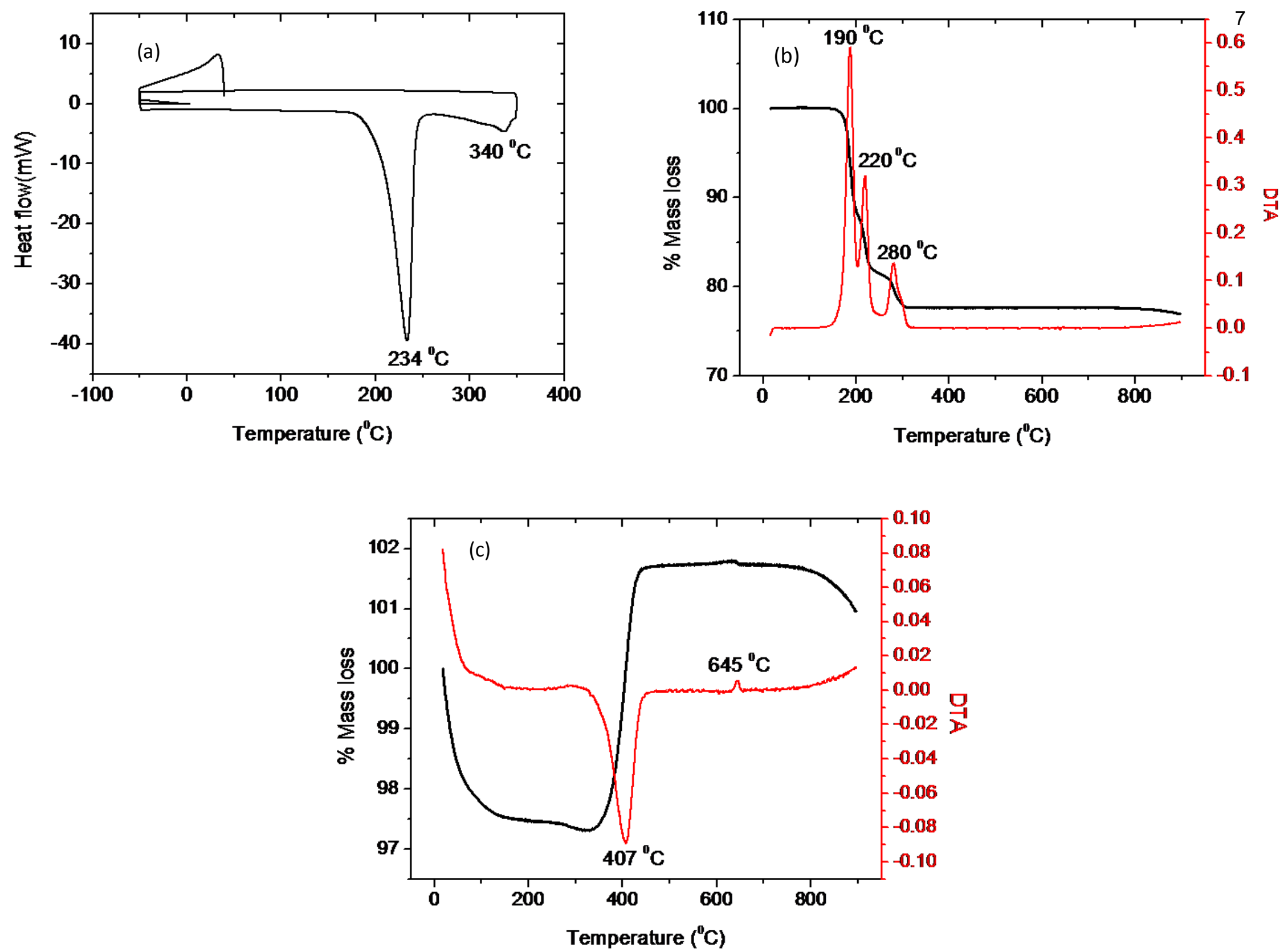

Figure 1 (a): DSC thermogram of the starting precursor (NH4VO3) (b): TGA/DTA thermogram of the starting precursor (NH4VO3) (c): TGA/DTA thermogram of the sample prepared at $4000 \mathrm{C}$ 
curve reveals mass loss in three regions during the scan as shown in the figure. The overall mass loss of $22.2 \%$ in the material was observed between $155.5{ }^{0} \mathrm{C}$ to $309{ }^{\circ} \mathrm{C}$; this value is in agreement with the one previously reported in the literatures [39-40].

However in this paper we have thoroughly analysed and accounted for each weight loss. Region one lies in the temperature range of $155.4-199{ }^{\circ} \mathrm{C}$, which is accompanied by a mass loss of $11.27 \%$. The mass loss in region twois found to be $6.41 \%$ within the temperature range of $199-231{ }^{0} \mathrm{C}$ and in the third region which falls in the temperature range of $231-$ $309{ }^{0} \mathrm{C}$, the loss was found to be $4.52 \%$.

The overall reaction occurs during the decomposition of $\mathrm{NH}_{4} \mathrm{VO}_{3}$ is shown in Eq. 1, the net mass loss of $22.2 \%$ was observed [40]. The major mass loss occurs due to the evaporation of $\mathrm{HN}_{3}$ and $\mathrm{H}_{2} \mathrm{O}$.

$$
2 \mathrm{NH}_{4} \mathrm{VO}_{3} \rightarrow \mathrm{V}_{2} \mathrm{O}_{5}+2 \mathrm{NH}_{3}+\mathrm{H}_{2} \mathrm{O}
$$

It is believed that the decomposition involve various reaction stages as shown in Eq. 2 to 5 [40-41]. In general, decomposition of $\mathrm{NH}_{4} \mathrm{VO}_{3}$ initiated according to $\mathrm{Eq} 2$ or 3.

$$
\begin{aligned}
& 6 \mathrm{NH}_{4} \mathrm{VO}_{3} \rightarrow\left(\mathrm{NH}_{4}\right)_{2} \mathrm{~V}_{6} \mathrm{O}_{16}+4 \mathrm{NH}_{3}+2 \mathrm{H}_{2} \mathrm{O} \\
& 4 \mathrm{NH}_{4} \mathrm{VO}_{3} \rightarrow\left(\mathrm{NH}_{4}\right)_{2} \mathrm{~V}_{4} \mathrm{O}_{11}+2 \mathrm{NH}_{3}+\mathrm{H}_{2} \mathrm{O} \\
& 3\left(\mathrm{NH}_{4}\right)_{2} \mathrm{~V}_{4} \mathrm{O}_{11} \rightarrow 2\left(\mathrm{NH}_{4}\right)_{2} \mathrm{~V}_{6} \mathrm{O}_{16}+2 \mathrm{NH}_{3}+\mathrm{H}_{2} \mathrm{O} \\
& \left(\mathrm{NH}_{4}\right)_{2} \mathrm{~V}_{6} \mathrm{O}_{16} \rightarrow 3 \mathrm{~V}_{2} \mathrm{O}_{5}+2 \mathrm{NH}_{3}+\mathrm{H}_{2} \mathrm{O}
\end{aligned}
$$

The net mass loss in Eq. 2, 3, 4 and 5 are calculated as 22.2, 11.11, 4.3 and $8.7 \%$ respectively. Representative calculation of mass loss in Eq. 3 is given in the supplementary material SM1 and the same was followed for Eq. 2, 4 and 5. However, the mass loss observed in region one $(11.27 \%)$ suggests decomposition of $\mathrm{NH}_{4} \mathrm{VO}_{3}$ initiated according to Eq. 3 . 
Thus the further decomposition of out product of Eq. 3 must follow the Eq. 4 and 5. The mass loss in region two $(6.41 \%)$ which is higher than the calculated value (Eq. 4). This may due to the simultaneous reactions according to Eq. 4 and 5. This simultaneous reaction is also suggested by the lower observed mass loss $(4.52 \%)$ in region three than the calculated $(8.7$ \%) from Eq. 5

Fig. 1(c) is a TGA/DTA profile of the sample prepared at $400{ }^{0} \mathrm{C}$ in synthetic nitrogen environment. The scan was performed over the temperature range of $26-900{ }^{0} \mathrm{C}$. The XRD profile (attached in SM3) of the powder before TAG measurement reveal the presence of $\mathrm{V}_{6} \mathrm{O}_{13}$. The initial reaction below $100{ }^{0} \mathrm{C}$ shows some loss in mass of the powder which may be due to the release of moisture absorbed by the powder. Further increase in temperature up to $335{ }^{0} \mathrm{C}$ reveals very small change in mass from 5.096 to $4.972 \mathrm{mg}$, which is $2.53 \%$. This is due to the reduction of $\mathrm{V}_{6} \mathrm{O}_{13}$. The possible reduction of $\mathrm{V}_{6} \mathrm{O}_{13}$ is shown in Eq. 6. Since the calculated mass loss in Eq. 6 is $3.09 \%$ (attached in SM2) which is very close to observed value.

$$
2 \mathrm{~V}_{6} \mathrm{O}_{13} \rightarrow 12 \mathrm{VO}_{2}+\mathrm{O}_{2}
$$

Above $340{ }^{0} \mathrm{C}$, significant mass gain was observed which was followed by the second stability around $440{ }^{\circ} \mathrm{C}$. The increase in mass is due to the oxygenation of $\mathrm{VO}_{2}$. The oxygen is contributed from the synthetic nitrogen flow during TGA experiment. The transformation is ascribed to $\mathrm{V}_{2} \mathrm{O}_{5}$ since it is known as a most stable oxide among vanadium oxides and usually formed above $340{ }^{0} \mathrm{C}$.

Fig. 2 shows the DSC profiles of the samples prepared by calcination of $\mathrm{NH}_{4} \mathrm{VO}_{3}$ from $100-350{ }^{0} \mathrm{C}$ in step of $50{ }^{\circ} \mathrm{C}$. The peaks at 185 and $220{ }^{\circ} \mathrm{C}$ for the sample calcined at $100{ }^{0} \mathrm{C}$ show exothermic reaction which may be due to the release of ammonia. Peaks at 78 


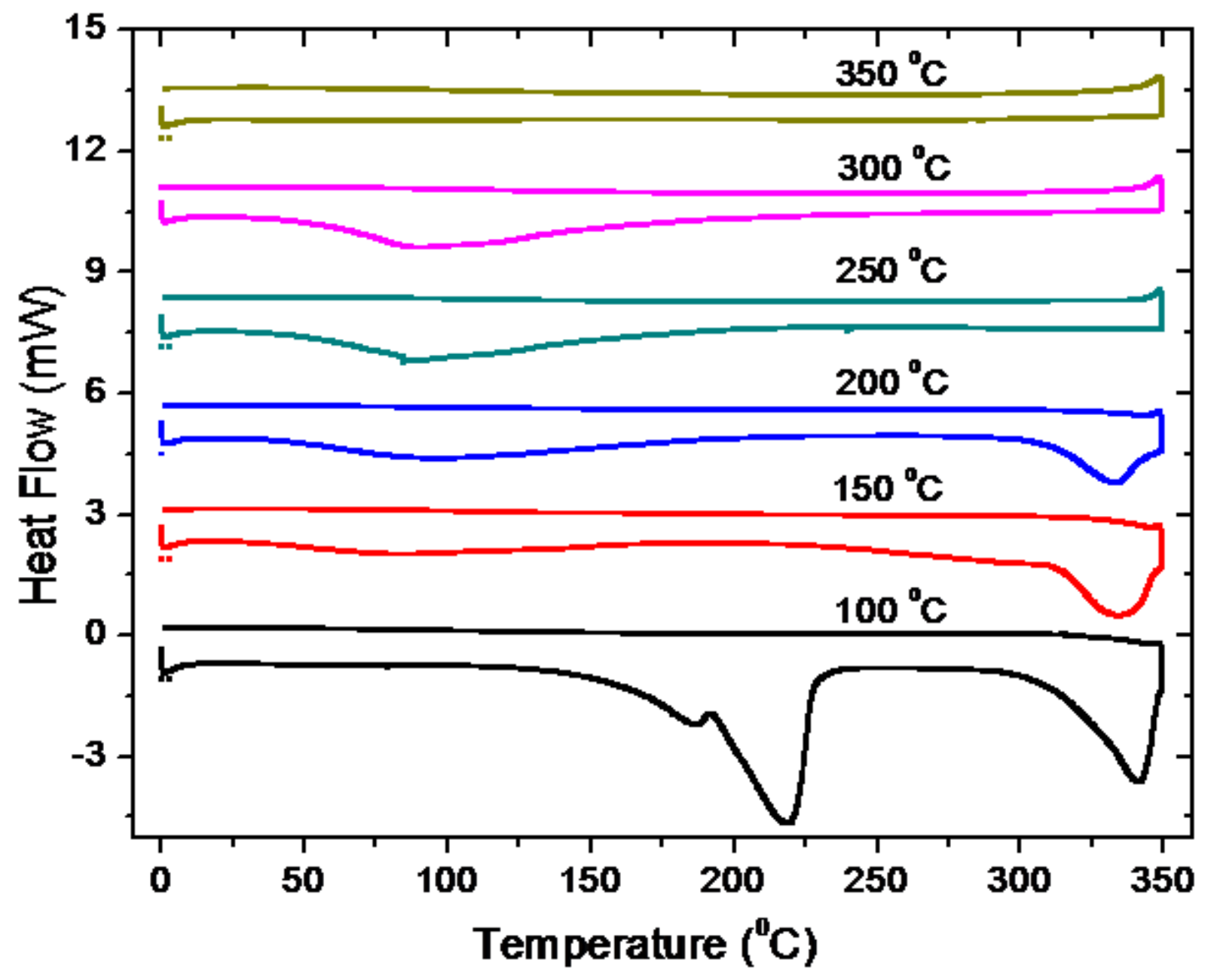

Figure 2: DSC thermograms of the samples prepared by calcination of NH4VO3 from $100-350$ 0C 
and $80{ }^{\circ} \mathrm{C}$ for the samples calcined at 150 and $200{ }^{\circ} \mathrm{C}$ may be due to the formation of $\mathrm{VO}_{2}$, since it is close to MIT temperature and the one at $85{ }^{\circ} \mathrm{C}$ for samples calcined at 250 and 300 ${ }^{0} \mathrm{C}$ may be due to the mixture of metastable phases of $\mathrm{VO}_{2}$ and $\mathrm{V}_{6} \mathrm{O}_{13}$. The formation of various phase with temperature was confirm with XRD pattern, discussed in section 3.2 and 3.4. The development of $\mathrm{V}_{2} \mathrm{O}_{5}$ phase was observed for the samples calcined at 100,150, and $200{ }^{0} \mathrm{C}$ in temperature region 310 to $340{ }^{\circ} \mathrm{C}$. The actual formation of $\mathrm{V}_{2} \mathrm{O}_{5}$ occurs at $375{ }^{0} \mathrm{C}$. Due to the limitation of DSC in terms of temperature range, we could not proceed for further higher temperature. Although this peak is absent in the case of sample calcined at 250 and 300 , this may due to peak shifting to the higher temperature $375{ }^{0} \mathrm{C}$. The sample calcined at $350{ }^{0} \mathrm{C}$ show optimum population of phase of $\mathrm{V}_{2} \mathrm{O}_{5}$,

\subsection{X-Ray diffraction Spectra}

XRD spectrum of the sample prepared at $400{ }^{0} \mathrm{C}$ depicts the monoclinic system of $\mathrm{V}_{6} \mathrm{O}_{13}$ by PCPDFWIN CAS No: 72-1278 with (110) plane as the dominant peak. The peaks were rather sharp, which indicate relatively high crystallinity of the particles. The average particle size was determined with Debye-Scherrer's model and found to be around $24 \mathrm{~nm}$. And X-ray diffraction pattern of the sample prepared at $500{ }^{0} \mathrm{C}$ also depicts orthorhombic system of $\mathrm{V}_{2} \mathrm{O}_{5}$ by PCDPDF CAS No: 89-0611 with dominant (101) planes and with presence of plane like (200), (310), (111), (411), (005). The average particle size of $26 \mathrm{~nm}$ was observed.

Fig. 3 (a) shows XRD spectra of the standard precursor $\mathrm{NH}_{4} \mathrm{VO}_{3}$ and samples calcined at temperatures $100-350{ }^{\circ} \mathrm{C}$. The XRD patterns were compared with PCDPDFWIN CAS No: 44-0252, 72-1278 and 89-0611 for $\mathrm{VO}_{2}, \mathrm{~V}_{6} \mathrm{O}_{13}$ and $\mathrm{V}_{2} \mathrm{O}_{5}$ respectively. Monoclinic peak of $\mathrm{VO}_{2}$ at $2 \theta$ (diffraction angle) $=27.8^{0}$ corresponding to the plane $(011)$ (PCDPDFWIN CAS No: 44-0252) is found to be dominant among the samples calcined at 100, 150 and 200 

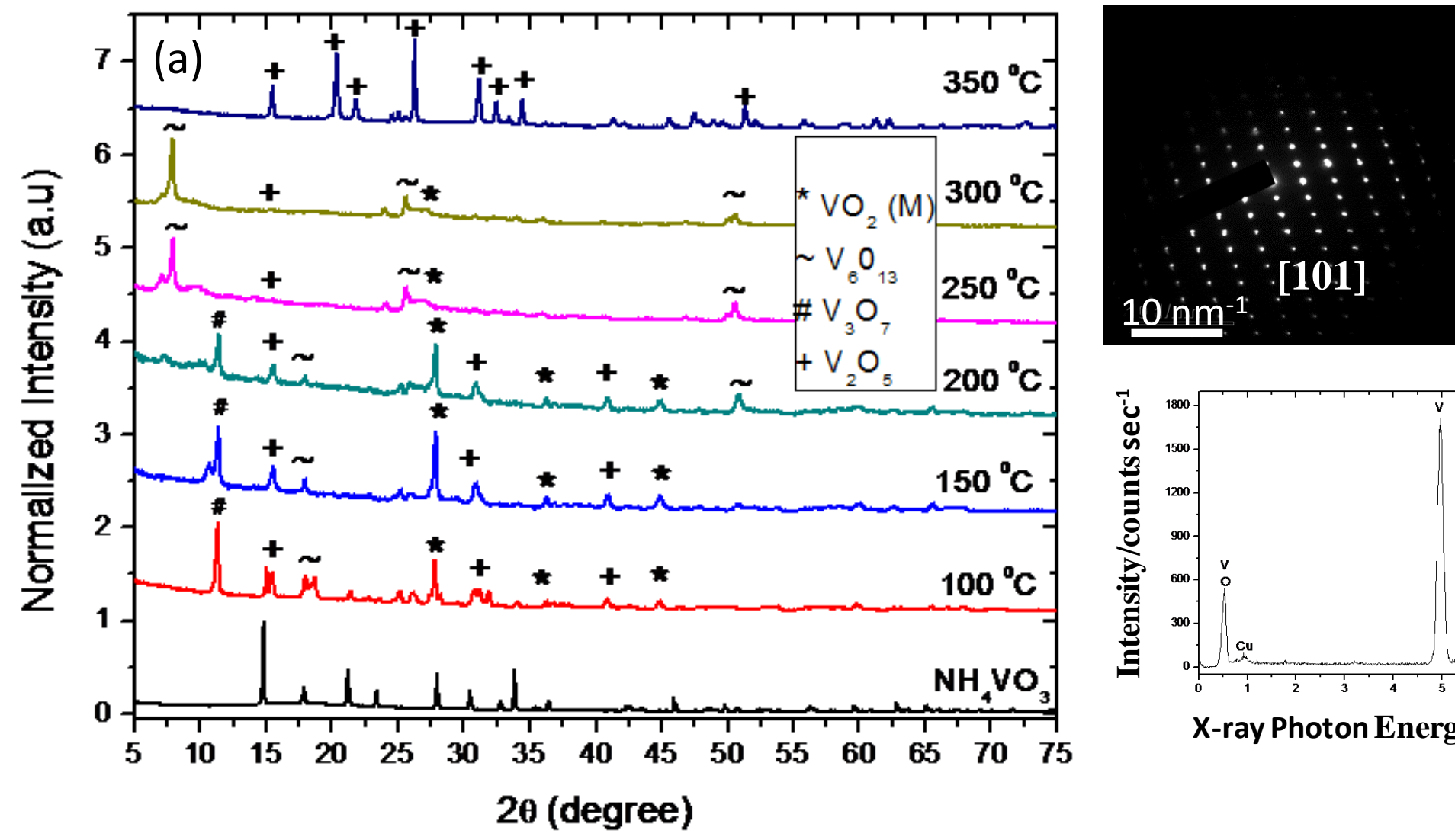

(b)

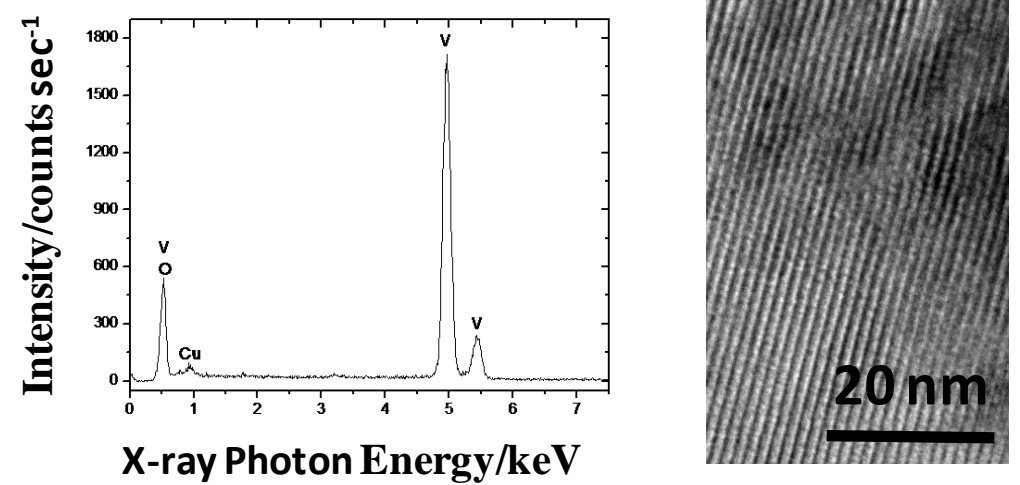

Figure 3 (a): $\mathrm{XRD}$ spectra of the standard $\mathrm{NH}_{4} \mathrm{VO}_{3}$ and of the samples prepared by calcination of $\mathrm{NH}_{4} \mathrm{VO}_{3}$ from 100 - $350{ }^{\circ} \mathrm{C}$, (b): High resolution TEM image of sample calcined at $350{ }^{\circ} \mathrm{C}$ showing single plane corresponding to that of 101 of $\mathrm{V}_{2} \mathrm{O}_{5}$, insert upper corner showing SAED pattern of 101 lattices and insert lower corner showing the corner showing SAED pattern of 101 lattices and insert lower corner showing the corresponding EDS spectrum 
${ }^{0} \mathrm{C}$. Various phases of vanadium oxide were also observed except for those samples calcined at 250 to $350{ }^{0} \mathrm{C}$. The sample prepared at 250 to $350{ }^{\circ} \mathrm{C}$ show the development of single phase of $\mathrm{V}_{2} \mathrm{O}_{5}$. Predominantly monoclinic metastable $\mathrm{V}_{6} \mathrm{O}_{13}$ was observed for the sample calcined at 250 and $300{ }^{\circ} \mathrm{C}$. Orthorhombic $\mathrm{V}_{2} \mathrm{O}_{5}$ was observed at $350{ }^{\circ} \mathrm{C}$.

\subsection{Transmission Electron Microscope}

TEM images for the calcined samples at $150{ }^{\circ} \mathrm{C}, 250{ }^{\circ} \mathrm{C}$ and $350{ }^{\circ} \mathrm{C}$ were carried out. fig. 3 (b) shows high resolution TEM image of sample calcined at $350{ }^{0} \mathrm{C}$ showing single plane corresponding to that of (101) of $\mathrm{V}_{2} \mathrm{O}_{5}$. Inset upper corner showing SAED pattern and lower corner showing the corresponding EDS spectrum. Sample calcined at $150{ }^{\circ} \mathrm{C}$ reveals sheet and rod like structure with SAED pattern of non-uniform diffraction. Single (110) plane of uniform diffraction corresponding to that of $\mathrm{V}_{6} \mathrm{O}_{13}$ was observed for the sample at $250{ }^{0} \mathrm{C}$. The radius is measured from Image J software and the lattice spacing was calculated to be 3.7 $\AA$ which is indexed to the monoclinic $\mathrm{V}_{6} \mathrm{O}_{13}$ parameters $(\mathrm{b}=3.671 \AA$ ). The calculated value of the lattice spacing for sample calcined at $350{ }^{0} \mathrm{C}$ is $3.483 \AA$ which is corresponding to orthorhombic $\mathrm{V}_{2} \mathrm{O}_{5}$ phase $(\mathrm{b}=3.517 \AA)$.

\subsection{Phase Diagram}

Fig. 4 is the phase evolution diagram showing the distribution of oxides $\left(\mathrm{VO}_{2}, \mathrm{~V}_{6} \mathrm{O}_{13}\right.$ and $\mathrm{V}_{2} \mathrm{O}_{5}$ ) with temperature. XRD pattern of sample calcined at various temperatures has been used to developed phase diagram. The phase analysis was carried out by calculating the area of Gaussian fitted XRD peaks. The percentage of phase was calculated using Eq. 7,

$$
\%\left(V O_{x}\right)=\frac{\sum A_{x}}{\sum A_{x}+\sum A_{y}+\ldots \ldots}
$$




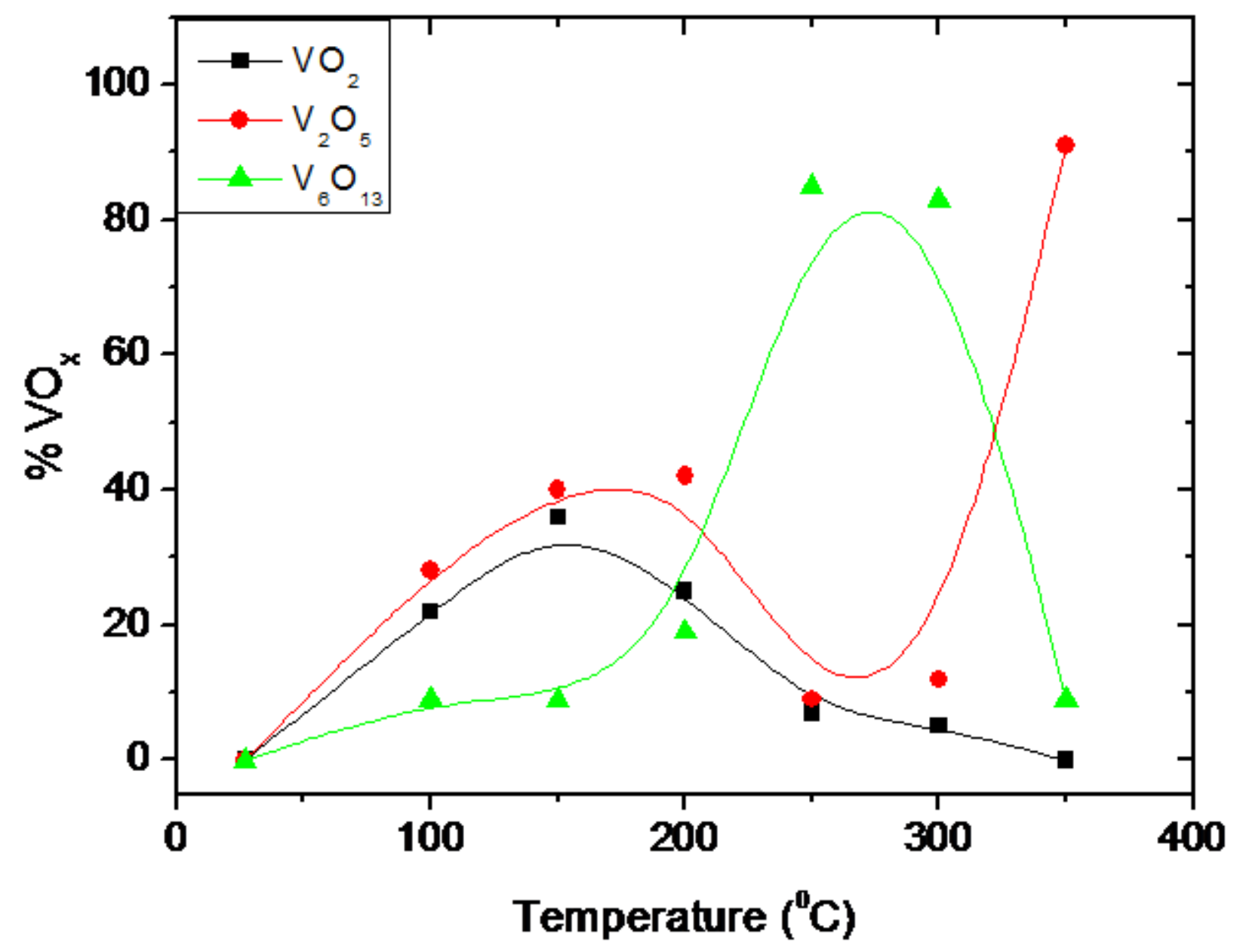

Figure 4: Vanadium Oxides (VO2, V6O13 and V2O5) Phase Evolution Diagram. 
where $A_{x}, A_{y} \ldots$. are the peak area corresponding to the phases $x, y \ldots$...espectively [47]. It was observed that formation of $\mathrm{VO}_{2}$ phase dominates in temperature range $150-200{ }^{\circ} \mathrm{C}$, whereas $\mathrm{V}_{6} \mathrm{O}_{13}$ phase is the dominant around $250-300{ }^{0} \mathrm{C} . \quad \mathrm{V}_{2} \mathrm{O}_{5}$ is found to be present for all temperatures and optimum population at $350{ }^{\circ} \mathrm{C}$.

\subsection{Raman Spectroscopy}

Raman spectroscopy is known to be a sensitive and reliable technique for crystal structure study in material science and engineering. This technique is based on the inelastic scattering of monochromatic light irradiated on the sample. The frequency of the scattered light usually collected and compared to that of the incident light. Raman spectrum of the sample prepared at $400{ }^{0} \mathrm{C}$ revels all Raman active modes of $\mathrm{V}_{6} \mathrm{O}_{13}$ [42]. A strong intense peak at lower frequency band $137 \mathrm{~cm}^{-1}$ correspond $\mathrm{B}_{\mathrm{g}}$ symmetry and the high frequency vibration at $990 \mathrm{~cm}^{-1}$ corresponding to stretching of O-V-O atoms was observed. Vibration modes such as 277,402 and $523 \mathrm{~cm}^{-1}$ are resulting from the bending mode of $\mathrm{V}-\mathrm{O}$ band and $686 \mathrm{~cm}^{-1}$ stretching mode corresponds to the motion parallel and perpendicular to ab-plane [43]. Raman vibrations of the sample prepared at $500{ }^{0} \mathrm{C}$ show frequencies $993,693,527$, $407,284,192,140 \mathrm{~cm}^{-1}$ vibrations corresponds modes of $\mathrm{V}_{2} \mathrm{O}_{5}$ [42-43].

Figure 5 (a) shows Raman spectra of the standard and calcined $\mathrm{NH}_{4} \mathrm{VO}_{3}$ precursor in the temperature range of $100-350{ }^{0} \mathrm{C}$. The presence of 194, 223, 265, 385, 600 and $628 \mathrm{~cm}^{-1}$ vibration modes in the samples calcined at $100-200{ }^{0} \mathrm{C}$ shows the predominant population of $\mathrm{VO}_{2}$ in this region [42]. The sample calcined at $250-350{ }^{0} \mathrm{C}$ shows peak at 137 , belong to $\mathrm{V}_{6} \mathrm{O}_{13}$ phase. The peak at 142 and $992 \mathrm{~cm}^{-1}$ belong to $\mathrm{V}_{2} \mathrm{O}_{5}$ phase $[42,43]$. The peaks extra at 265 and $385 \mathrm{~cm}^{-1}$ revels the presence of $\mathrm{VO}_{2}$ phase at higher temperatures. The peak due to ammonia vibrations is observed around $1420 \mathrm{~cm}^{-1}$ for precursor $\mathrm{NH}_{4} \mathrm{VO}_{3}$ [44]. 


\subsection{Fourier Transform Infrared Spectroscopy (FT-IR)}

FT-IR is a rotational vibrational spectroscopic technique that is based on the absorption of photon by the molecules constituting a material. Molecule absorbs the incident photon and promote to higher energy state (excited state). The changes in energy of incident photon due to the absorption were detected. Fig.5 (b) shows the FTIR spectra of the standard and calcined $\mathrm{NH}_{4} \mathrm{VO}_{3}$ precursor in the temperature range of $100-350{ }^{\circ} \mathrm{C}$.

The observed absorption shoulder at $715 \mathrm{~cm}^{-1}$ and strong peak at $972 \mathrm{~cm}^{-1}$ are correspond to the $\mathrm{VO}_{2}$ [45], The shoulder at $715 \mathrm{~cm}^{-1}$ was not observe for higher temperature $\left(250-350{ }^{0} \mathrm{C}\right)$ and the shift in $972 \mathrm{~cm}^{-1}$ peak was observed at $350{ }^{0} \mathrm{C}$. The peak shifted to higher frequency $1009 \mathrm{~cm}^{-1}$ at $350{ }^{0} \mathrm{C}$ corresponding to single polycrystalline $\mathrm{V}_{2} \mathrm{O}_{5}$ phase [45]. The presence of both shoulder and strong peak at lower temperature $\left(100-200{ }^{0} \mathrm{C}\right)$ reveals the higher population of $\mathrm{VO}_{2}$. The higher population of $\mathrm{V}_{2} \mathrm{O}_{5}$ at higher temperature and $\mathrm{VO}_{2}$ at lower temperature is also supported by our XRD phase calculation and Raman study.

\subsection{Brunauer-Emmett-Teller (BET)}

Brunauer-Emmiter-Teller theory relies on the physical adsorption (physisorption) of gas molecules on the surface of solid-state materials. This technique gives information about the specific surface area of a nano-material. This theory is an extension of Langmuir theory which described the amount of adsorbs molecules (adsorbate) on the surface of material (adsorbent) as a function of pressures or concentration [46]. BET equation is expressed below in Eq. (8),

$$
\frac{1}{v\left(\frac{p_{0}}{p}-1\right)}=\frac{c-1}{v_{m} c}\left(\frac{p}{p_{0}}\right)+\frac{1}{v_{m} c}
$$

where $p$ and $p_{0}$ are the equilibrium and saturation pressure of adsorbate at the temperature of adsorption, $v$ is the adsorbed gas quantity, $v_{m}$ is the monolayer adsorbed gas quantity and $c$ is the BET constant. 

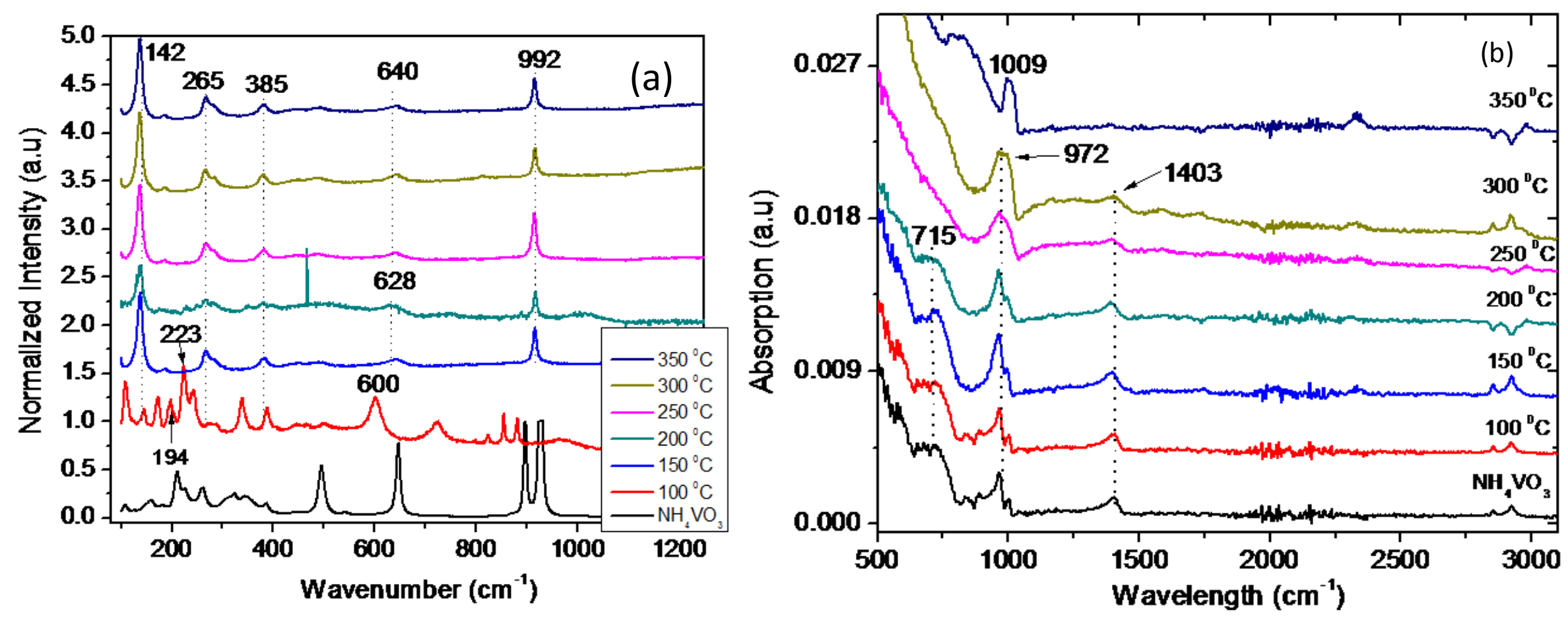

Figure 5: (a): Raman spectra of the standard $\mathrm{NH}_{4} \mathrm{VO}_{3}$ and of the samples prepared by calcination of $\mathrm{NH}_{4} \mathrm{VO}$ from 100 to $350{ }^{\circ} \mathrm{C}$ (b): $\mathrm{FT}$-IR of the standard $\mathrm{NH}_{4} \mathrm{VO}_{3}$ and of the samples prepared by calcination of $\mathrm{NH}_{4} \mathrm{VO}_{3}$ from 100 to $350{ }^{\circ} \mathrm{C}$. 

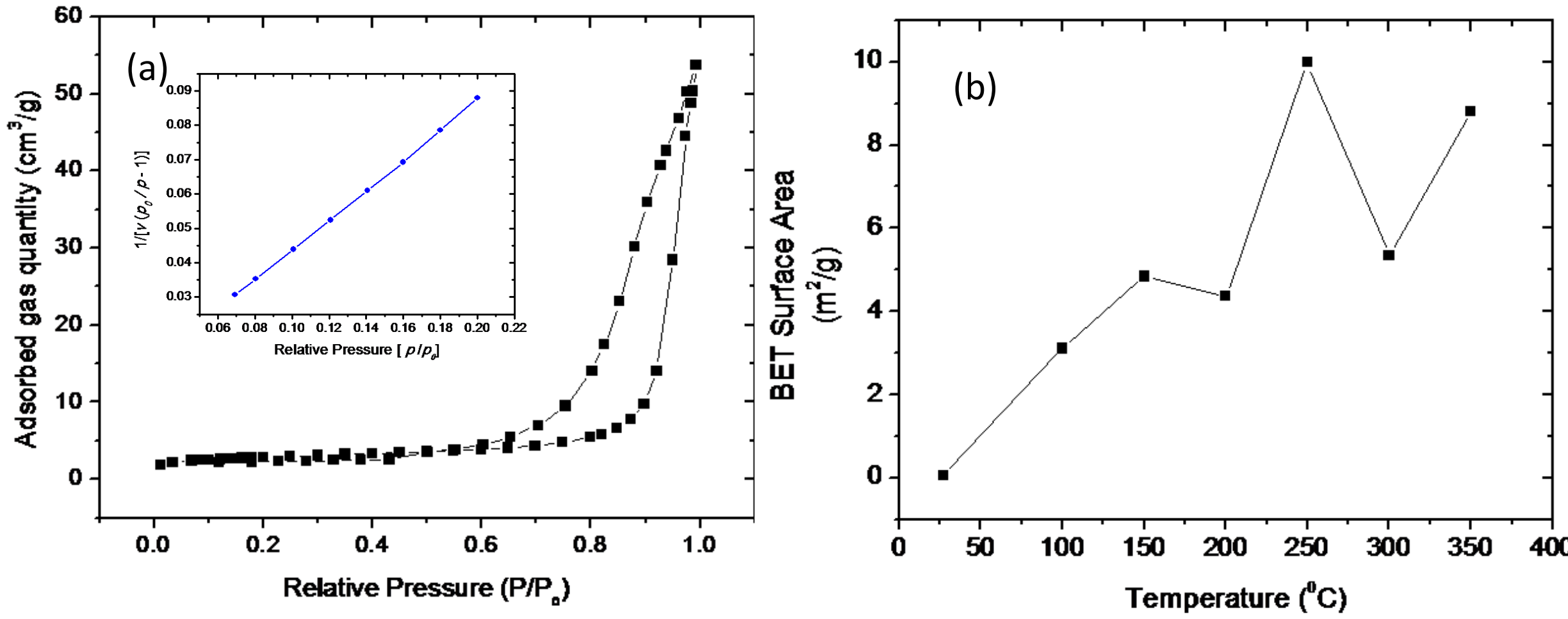

Figure 6: (a): N2 adsorption and desorption isotherms profile of the powder calcined at $250{ }^{\circ} \mathrm{C}$, insert is the BET plot, (b): $\mathrm{BET}$ surface area versus temperature for all the calcined powders and including $\mathrm{NH}_{4} \mathrm{VO}_{3}$. 


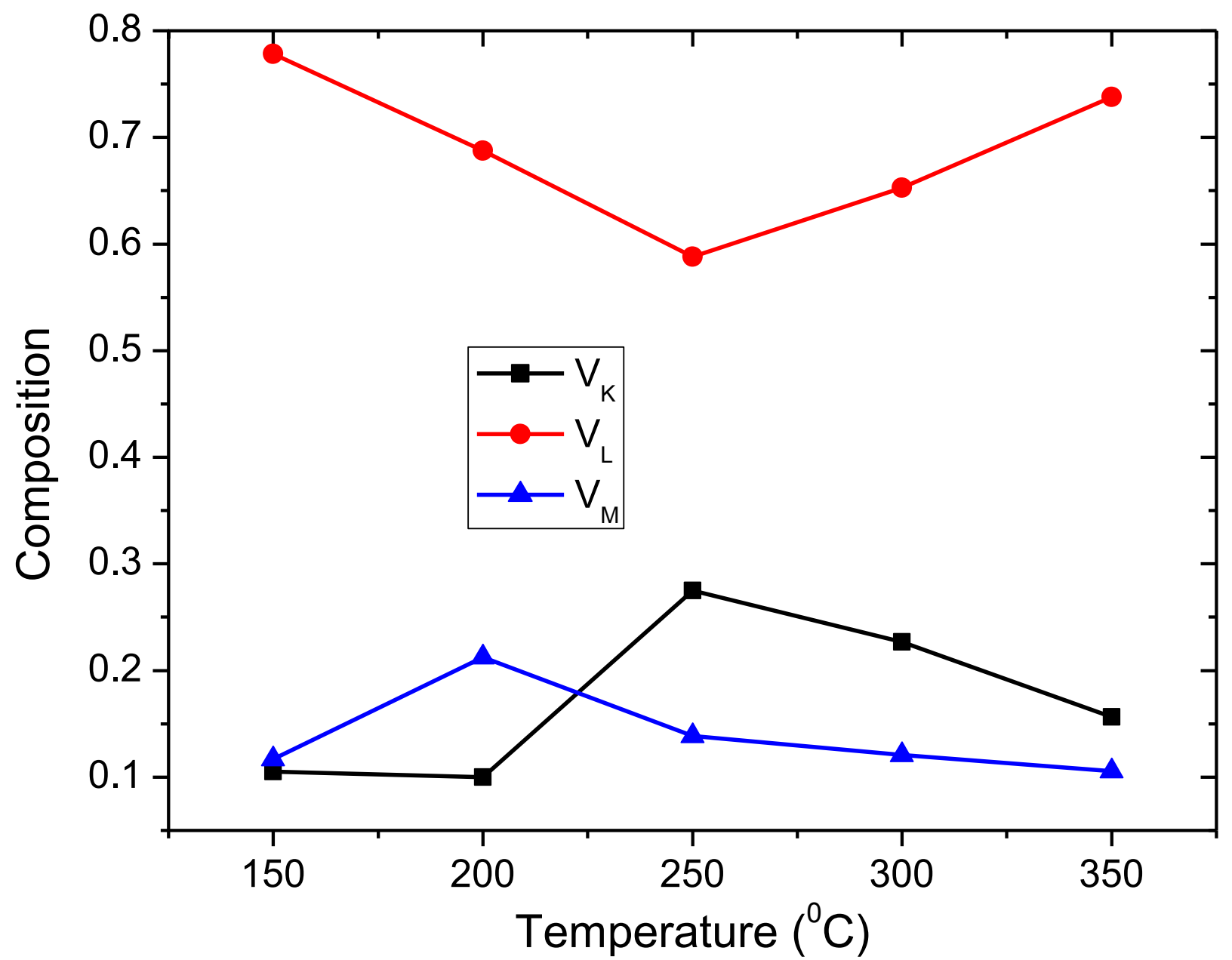

Figure 7: Proportions of V2O5, VO2 and V6O13 determined by EDS calibrated with XPS as they vary with annealing temperature. 
The BET measurements were carried out for standard and calcined $\mathrm{NH}_{4} \mathrm{VO}_{3}$ at various temperatures 100 to $350^{\circ} \mathrm{C}$. The change in $\mathrm{N}_{2}$ adsorption with partial pressure for the sample calcined at $250{ }^{\circ} \mathrm{C}$ is shown in figure 6(a). The monolayer adsorbed gas $v_{m}$ and BET constant $c$ were measure as the intercept of linear plot of $1 / v\left(p_{0} / p-1\right)$ and $\mathrm{p} / \mathrm{p}_{0}$, shown in inset image fig. 6(a). The BET surface area $\left(\mathrm{S}_{\mathrm{BET}}=v_{m} \cdot N_{s} / V a\right.$, where $N s$ is Avogadros number, $V$ is molar volume of adsorbate gas and $a$ is the mass of the adsorbent) of calcined samples were calculated and are shown in fig. 6 (b). The surface area is found to increase with the calcination temperatures. It follows the Langmuir isotherms pattern with temperatures.

\subsection{XPS and EDS}

We have performed XPS on a reference sample containing known mixed $\mathrm{V}^{3+}, \mathrm{V}^{4+}$ and $\mathrm{V}^{5+}$ phases of $\mathrm{VO}_{\mathrm{x}}$ as well EDS of the same reference sample. The full XPS and EDS spectra this reference sample was reported in our recent paper [48]. This analysis has been used to calibrate all EDS results for the our current samples containing $\mathrm{V}_{6} \mathrm{O}_{13}, \mathrm{VO}_{2}$ and $\mathrm{V}_{2} \mathrm{O}_{5}$. The analysis results are summarized in Table 1. First the heights and the widths of the peaks were determined for each peak in XPS and in EDS and areas under such peaks were calculated. The proportions were determined from the ratio of the area under each peak to the total of all peaks considered [47].

From Table 1 (a) the reference sample has $69 \%$ proportion of $\mathrm{V}_{2} \mathrm{O}_{5}$ or a contribution from mixed (metastable) $\mathrm{V}_{6} \mathrm{O}_{13}$ and the rest $31 \%$ of the photo-electrons come from $\mathrm{VO}_{2}$ with a small contribution from $\mathrm{V}_{6} \mathrm{O}_{13}$ again. EDS results of the same sample indicate $70 \% \mathrm{X}$-ray emission from $\mathrm{V}_{\mathrm{L}}$ electronic shell. This could be attributed to $\mathrm{V}_{2} \mathrm{O}_{5}$ and a small contribution from the mixed phase $\mathrm{V}_{6} \mathrm{O}_{13}$ as suggested by XPS in Table 1 (a). EDS This shows that XPS 
Table 1 (a): XPS analysis for reference or standard sample containing VO2, V2O5, V6O13 and WO3.

\begin{tabular}{|l|r|r|r|r|r|r|}
\hline Orbitals & Height, $\mathrm{H}$ (a.u) & H0 (a.u.) & Width, W (eV) & A & $\%$ V + W & \% of $\mathrm{V}^{1+}$ \\
\hline $\mathrm{W}(4 \mathrm{f})_{7 / 2}, \mathrm{~W}^{6+}$ & 2100 & 150 & 3 & 5850 & 51.5 & \\
\hline $\mathrm{W}(4 \mathrm{f})_{5 / 2}, \mathrm{~W}^{6+}$ & 1600 & 250 & 3 & 4050 & 35.6 & \\
\hline $\mathrm{V}(2 \mathrm{p})_{3 / 2}, \mathrm{~V}^{4+}$ & 3500 & 3200 & 1.5 & 450 & 3.9 & 30.8 \\
\hline $\mathrm{V}(2 \mathrm{p})_{3 / 2}, \mathrm{~V}^{5+}$ & 3975 & 3300 & 1.5 & 1012.5 & 8.9 & 69.2 \\
\hline
\end{tabular}

Table 1 (b): EDS analysis for reference or standard sample containing VO2, V2O5, V6O13 and WO3.

\begin{tabular}{|l|r|r|r|r|}
\hline Electronic shell & Height, $\mathrm{H}(\mathrm{a} . \mathrm{u})$ & Width, W (eV) & \multicolumn{1}{c|}{$\mathrm{A}$} & \% of $\mathrm{V}^{\mathrm{i}+}$ \\
\hline $\mathrm{V}_{\mathrm{M}}$ & 500 & 0.2 & 100 & 15.6 \\
\hline $\mathrm{V}_{\mathrm{L}}$ & 1500 & 0.3 & 450 & 70.3 \\
\hline $\mathrm{V}_{\mathrm{K}}$ & 300 & 0.3 & 90 & 14.1 \\
\hline
\end{tabular}


and EDS results are in good agreement and one can use local EDS results with this XPS calibration to determine the local composition of the current $\mathrm{VO}_{\mathrm{x}}$ materials.

One can conclude the the $V_{L}$ shell peak in EDS can be used to mark $V_{2} \mathrm{O}_{5}$ whereas the $V_{M}$ and $\mathrm{V}_{\mathrm{K}}$ shells are mostly for $\mathrm{VO}_{2}$ although in both cases $\mathrm{V}_{6} \mathrm{O}_{13}$ has a strong indeterminate influence. One can understand the $\mathrm{V}_{6} \mathrm{O}_{13}$ poses a challenge in ascertaining its exact contribution owing to its meta-stable nature.

We have summarized the EDS analysis results from the VOx samples annealed at 150, 200, 250, 300 and $350{ }^{\circ} \mathrm{C}$ based on the calibration undertaken in Tables 1 (a) and 1(b). These results are summarized in Table 2. It can be observed that the proportions of the phases change with annealing temperature. The changes are plotted in Figure 7 . The $\mathrm{V}_{\mathrm{L}}-$ temperature profile shows a decrease from $100{ }^{\circ} \mathrm{C}$ to $250{ }^{\circ} \mathrm{C}$ and then increases again up to the annealing temperature of $350{ }^{\circ} \mathrm{C}$. This profile agrees very well with the phase diagram shown in Figure 4 in the previous section. Similarly, the proportions determined from $V_{M}$ peak at $150{ }^{\circ} \mathrm{C}$ which is exactly the $\mathrm{VO}_{2}$ profile in the phase diagram in Figure 4 whereas the proportions calculated from $\mathrm{V}_{\mathrm{K}}$ shell increase to a maximum value at an annealing temperature of $200{ }^{\circ} \mathrm{C}$ which agrees with the $\mathrm{V}_{6} \mathrm{O}_{13}$ profile in Figure 4. This assures us that the present XPS calibration of the EDS results is correct.

\subsection{Vibrating Sample Magnetometry (VSM)}

The traditional definitions of remanent magnetization $\left(\mathrm{M}_{\mathrm{R}}{ }^{+}\right.$and $\left.\mathrm{M}_{\mathrm{R}}{ }^{-}\right)$, saturation magnetization $\left(\mathrm{M}_{\mathrm{S}}{ }^{+}\right.$and $\left.\mathrm{M}_{\mathrm{S}}{ }^{-}\right)$and squareness (SQ) in bulk and nano-scale magnetic materials are schematically illustrated in Figure 8 ( $(\mathrm{a}$ and $\mathrm{b}$ ). It should be noted that nano-materials display a shift of the hysteresis loop due to what is called exchange bias $[48,49]$. In Figure 8 
Table 2: EDS analysis based on the calibrations in Tables 1 (a) and (b) and local composition for the VOx samples annealed at 150, 200, 250, 300 and $350 \mathrm{C}$

\begin{tabular}{|l|l|r|r|r|r|}
\hline Sample & Electronic shell & Height, H (a.u) & Width, W (eV) & A & \% of Vi+ \\
\hline EDX 150 & $\mathrm{V}_{\mathrm{M}}$ & 900 & 0.15 & 135 & 10.5 \\
\hline & $\mathrm{V}_{\mathrm{L}}$ & 5000 & 0.2 & 1000 & 77.8 \\
\hline & $\mathrm{V}_{\mathrm{K}}$ & 750 & 0.2 & 150 & 11.7 \\
\hline EDX 200 & $\mathrm{V}_{\mathrm{M}}$ & 800 & 0.1 & 80 & 10.0 \\
\hline & $\mathrm{V}_{\mathrm{L}}$ & 5500 & 0.1 & 550 & 68.8 \\
\hline & $\mathrm{V}_{\mathrm{K}}$ & 850 & 0.2 & 170 & 21.2 \\
\hline EDX 250 & $\mathrm{V}_{\mathrm{M}}$ & 530 & 0.15 & 79.5 & 27.5 \\
\hline & $\mathrm{V}_{\mathrm{L}}$ & 1700 & 0.1 & 170 & 58.7 \\
\hline & $\mathrm{V}_{\mathrm{K}}$ & 200 & 0.2 & 40 & 13.8 \\
\hline EDX 300 & $\mathrm{V}_{\mathrm{M}}$ & 250 & 0.15 & 37.5 & 22.7 \\
\hline & $\mathrm{V}_{\mathrm{L}}$ & 720 & 0.15 & 108 & 65.2 \\
\hline & $\mathrm{V}_{\mathrm{K}}$ & 100 & 0.2 & 20 & 12.1 \\
\hline EDX 350 & $\mathrm{V}_{\mathrm{M}}$ & 990 & 0.15 & 148.5 & 15.7 \\
\hline & $\mathrm{V}_{\mathrm{L}}$ & 3500 & 0.2 & 700 & 73.8 \\
\hline & $\mathrm{V}_{\mathrm{K}}$ & 500 & 0.2 & 100 & 10.5 \\
\hline
\end{tabular}




\section{(a) bulk}
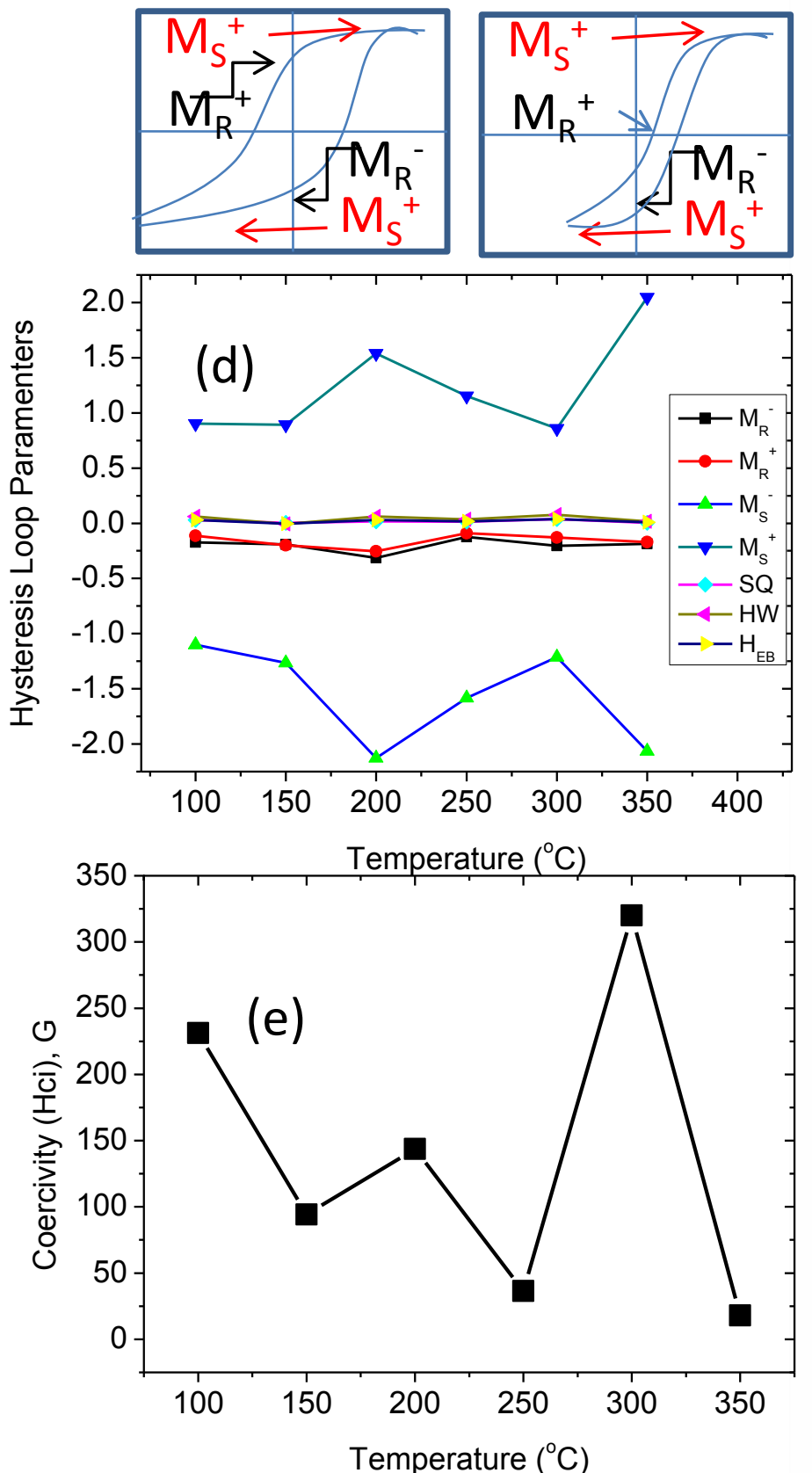

(c) 24

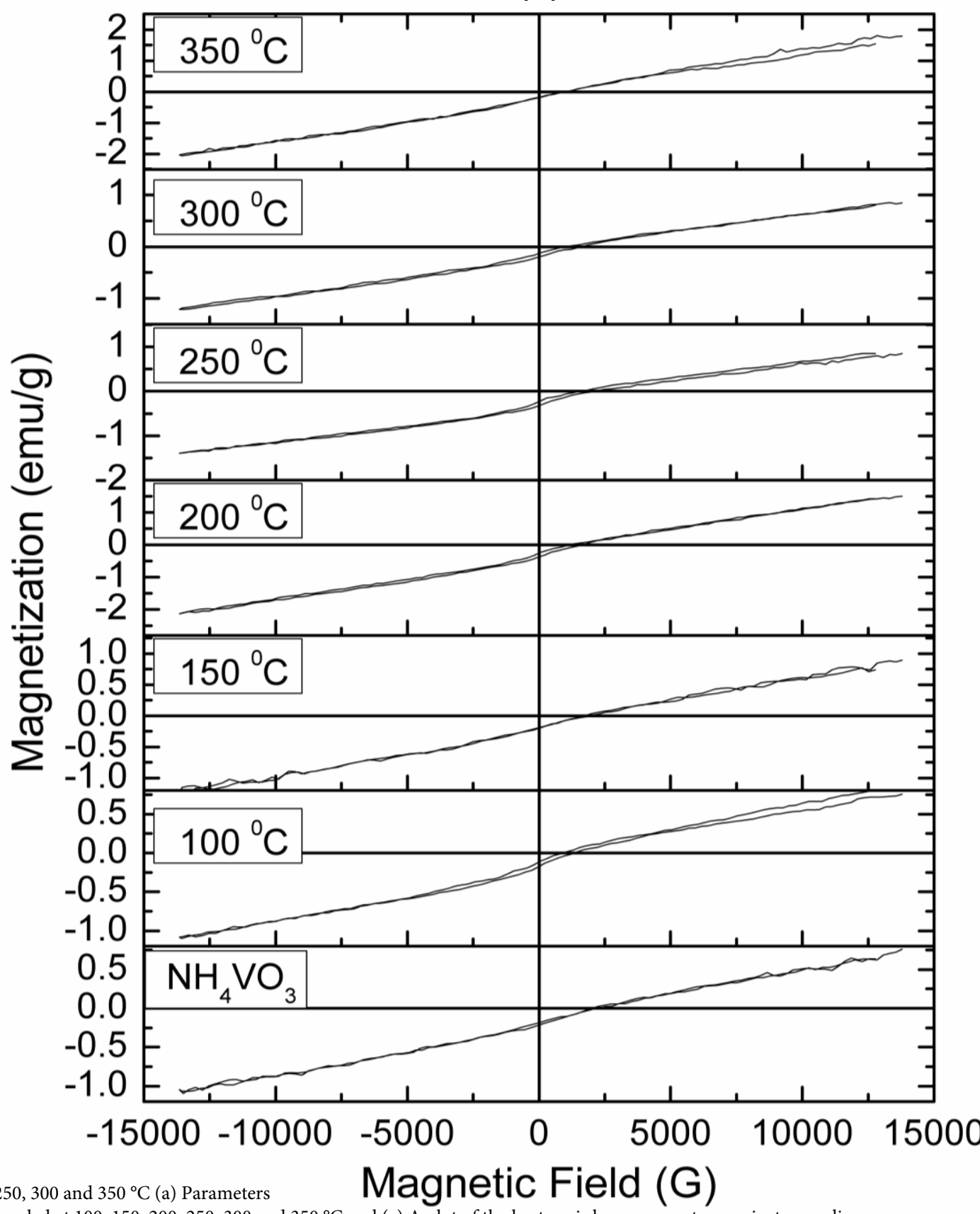


(c) we show that hysteresis loops for all $\mathrm{VO}_{\mathrm{x}}$ samples annealed at 100, 150, 200, 250, 300 and $350{ }^{\circ} \mathrm{C}$ including the precursor materials of ammonium metavanadate, $\mathrm{NH}_{4} \mathrm{VO}_{3}$. One can note that all samples show a degree of shift in the hysteresis loops which reveals that all the powders are nano-scale materials. As to whether these materials are ferro- or ferri- or paramagnetic, the loops show very small amount of squareness, of the order of $10^{-2}$, and a very small opening in the loops [typical values of $\mathrm{H}_{\mathrm{c}}{ }^{+}-\mathrm{H}_{\mathrm{c}}{ }^{-}$of the order of $10^{-2}$ ]. This points to the fact that these materials are largely para-magnetic. However, there is a finite coercivity (Figure $8 \mathrm{~d}$ and e) in samples (from 17 to $300 \mathrm{G}$ ) showing there is a degree of ferro-magnetic order in this paramagnetic matrix.

In Table 3 we give a summary of the parameters of remanent magnetization $\left(\mathrm{M}_{\mathrm{R}}{ }^{+}\right.$and $\left.\mathrm{M}_{\mathrm{R}}{ }^{-}\right)$, saturation magnetization $\left(\mathrm{MS}_{\mathrm{S}}^{+}\right.$and $\left.\mathrm{M}_{\mathrm{S}}{ }^{-}\right)$and squareness (SQ) as well hysteresis width and exchange bias width obtained from the hysteresis loops given in Figure 8 (b). The hysteresis width has been estimated to be proportional to the loop opening in the vertical axis which is the difference between $\mathrm{M}_{\mathrm{R}}{ }^{+}$and $\mathrm{M}_{\mathrm{R}}{ }^{-}$.

$$
H W \propto\left(M_{R}^{+}-M_{R}^{-}\right)=k\left(M_{R}^{-}(\text {high })-M_{R}^{-}(\text {low })\right)
$$

The exchange bias width has been estimated to be half of this opening as previous done [50].

$$
H_{E B} \propto \frac{\left(M_{R}^{+}-M_{R}^{-}\right)}{2}=\frac{k}{2}\left(M_{R}^{-}(\text {high })-M_{R}^{-}(\text {low })\right)
$$

A plot of these parameters for all annealed samples is given in Figure $8(\mathrm{~d}, \mathrm{e})$ and it is interesting to note that coercivity generally decreases with annealing temperature although it shows a high point at $300{ }^{\circ} \mathrm{C}$ whereas remanent magnetization $\left(\mathrm{M}_{\mathrm{R}}{ }^{+}\right.$and $\left.\mathrm{M}_{\mathrm{R}}{ }^{-}\right)$, saturation magnetization $\left(\mathrm{M}_{\mathrm{S}}{ }^{+}\right.$and $\left.\mathrm{M}_{\mathrm{S}}{ }^{-}\right)$all show the lowest values at $200{ }^{\circ} \mathrm{C}$. At the former temperature, it is interesting to note that this is a transition temperature from $\mathrm{V}_{6} \mathrm{O}_{13}$ to $\mathrm{V}_{2} \mathrm{O}_{5}$ 
Table 3 A summary of the hysteresis loop parameters of remanent magnetization (MR+ and MR-), saturation magnetization (MS+ and MS-) and squareness (SQ) as well hysteresis width and exchange bias width

\begin{tabular}{|r|r|l|l|l|l|r|r|r|}
\hline Annealing & Coercivity & MR & MR & MS & MS & Squareness & $\begin{array}{l}\text { Loop } \\
\text { opening }\end{array}$ & $\begin{array}{l}\text { Exchange } \\
\text { bias }\end{array}$ \\
\hline Temp oC & (Hci), G & $\begin{array}{l}\text { Negative, } \\
\text { emu/g }\end{array}$ & $\begin{array}{l}\text { Posit } \\
\text { ive, } \\
\text { emu/ } \\
\mathrm{g}\end{array}$ & $\begin{array}{l}\text { Negative, } \\
\text { emu/g }\end{array}$ & $\begin{array}{l}\text { Positive, } \\
\text { emu/g }\end{array}$ & & & \\
\hline 100 & 231.12 & -0.17 & -0.11 & -1.10 & 0.90 & 0.03 & 0.06 & 0.03 \\
\hline 150 & 94.32 & -0.19 & -0.20 & -1.26 & 0.89 & 0.00 & -0.01 & 0.00 \\
\hline 200 & 143.64 & -0.31 & -0.25 & -2.13 & 1.54 & 0.02 & 0.06 & 0.03 \\
\hline 250 & 36.42 & -0.12 & -0.09 & -1.58 & 1.15 & 0.01 & 0.04 & 0.02 \\
\hline 300 & 320.09 & -0.20 & -0.13 & -1.21 & 0.86 & 0.04 & 0.08 & 0.04 \\
\hline 350 & 17.90 & -0.19 & -0.17 & -2.06 & 2.05 & 0.00 & 0.02 & 0.01 \\
\hline
\end{tabular}


(a)

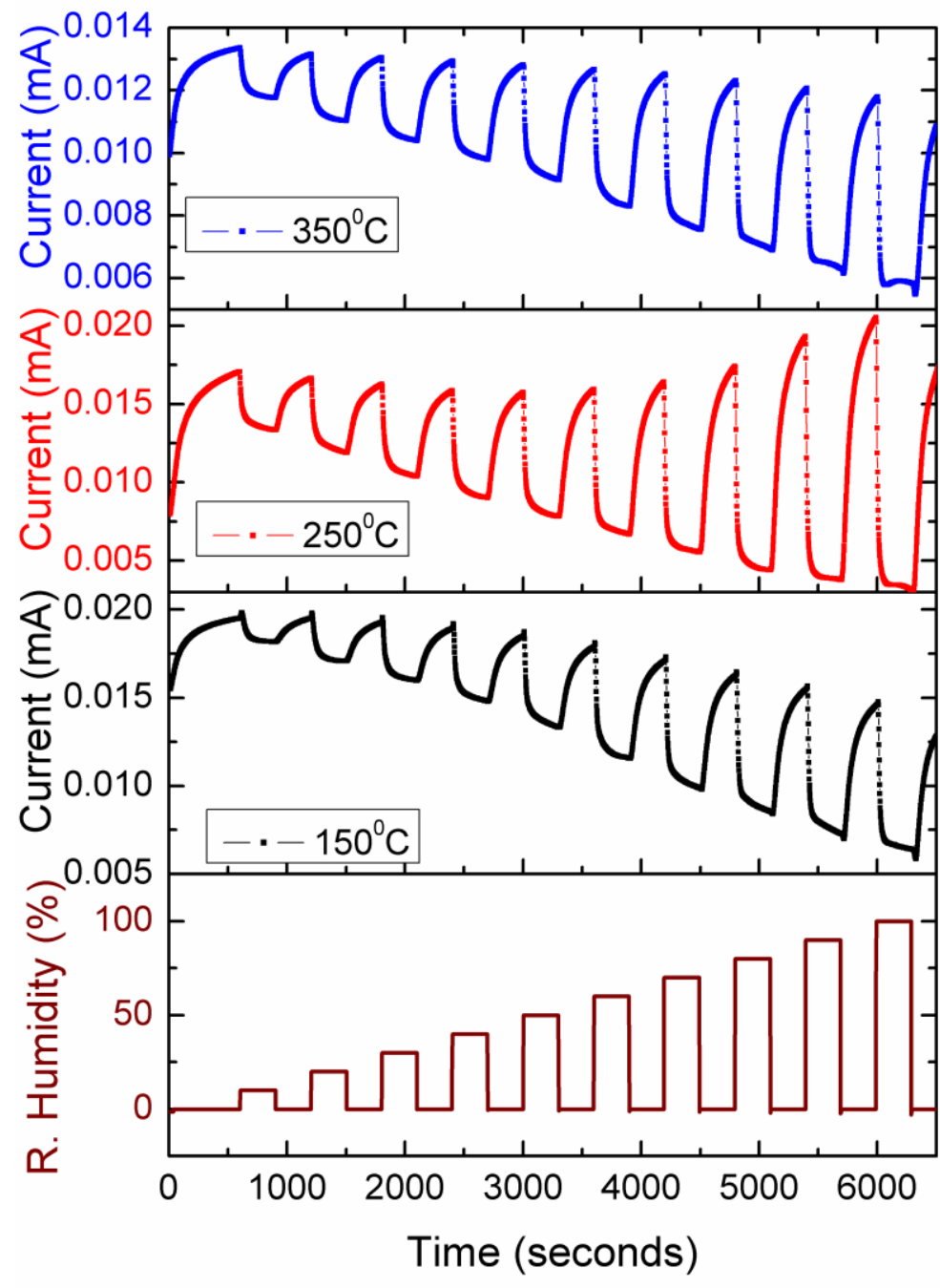

(b)

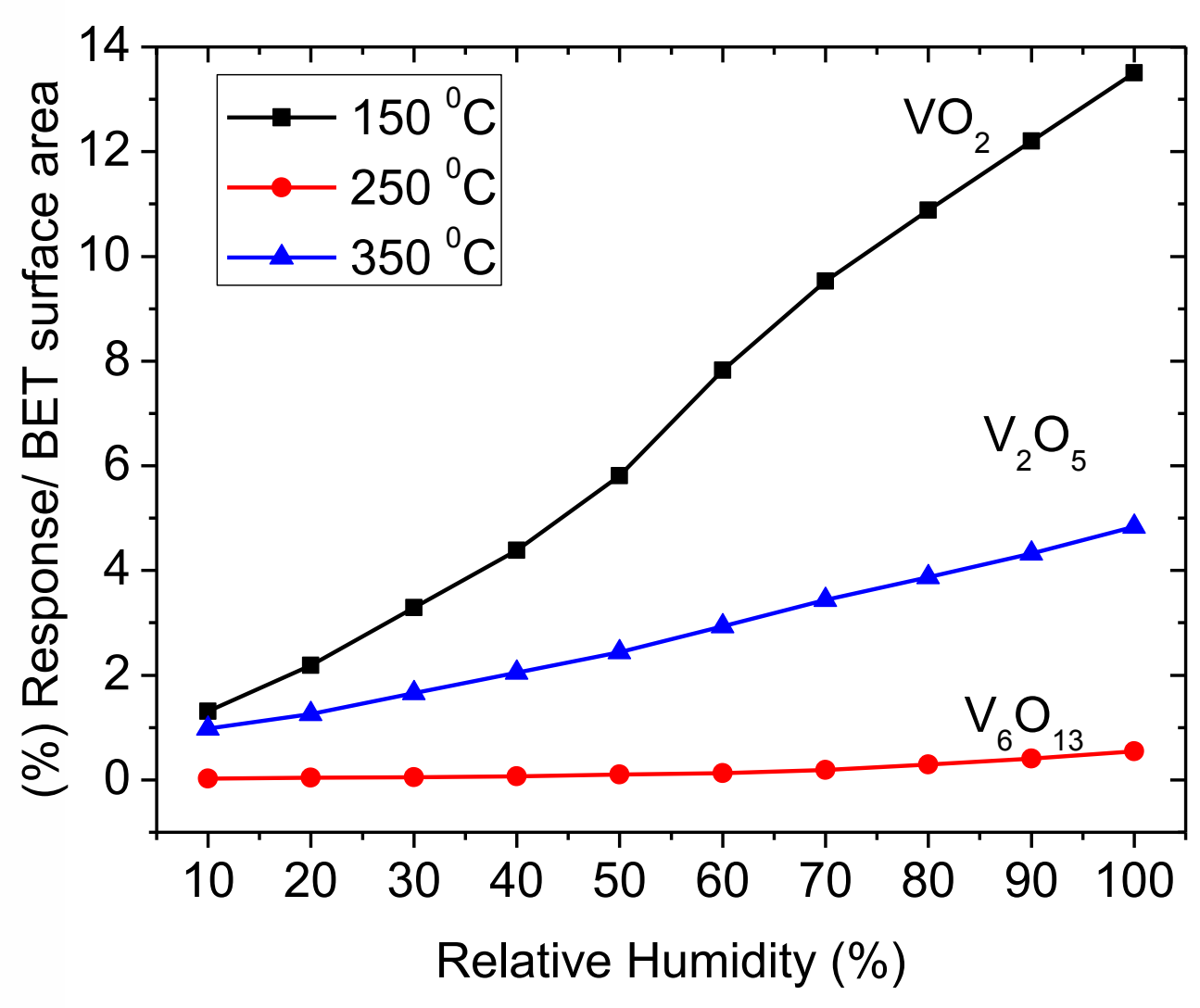

Figure 9: (a) Transient profiles of current through the VOx samples in varying levels of humidity (b) Responses weighted against BET surface area for VOx samples as function of humidity level. 
and the latter is a transition temperature from $\mathrm{VO}_{2}$ to $\mathrm{V}_{6} \mathrm{O}_{13}$. VSM confirms the following order of appearance: $\mathrm{VO}_{2} \rightarrow \mathrm{V}_{6} \mathrm{O}_{13} \rightarrow \mathrm{V}_{2} \mathrm{O}_{5}$ as temperatures of annealing are elevated.

\subsection{Applications: Humidity Sensing.}

We have shown before how $\mathrm{VO}_{2}$ has been employed in sensing of hydrogen [51,52]. In this present report, we have also subjected the $\mathrm{VO}_{\mathrm{x}}$ samples annealed at $150{ }^{\circ} \mathrm{C}\left(\mathrm{VO}_{2}\right), 250{ }^{\circ} \mathrm{C}$ $\left(\mathrm{V}_{6} \mathrm{O}_{13}\right)$ and $350{ }^{\circ} \mathrm{C}$ to sensing of humidity. The transient profiles of the current through the sample placed on inter-digitated electrodes in the presence or absence of varying humidity levels are shown in Figure 9 (a). Each time the humidity level is allowed in the chamber, the current through the samples decreases. This means that all VOx samples gain resistance upon interaction with water vapour. Since all these VOx phases are known to show n-type conductivity, we could explain the increase in resistance as an indication of water molecules taking away electrons or O2- species from VOx surfaces during adsorption but releasing these electrons back on desorption. In Figure 9 (b) we plot response [defined as $S=\left(\mathrm{I}_{\text {out }^{-}}\right.$ $\left.\left.\mathrm{I}_{\mathrm{in}}\right) / \mathrm{I}_{\mathrm{in}}\right]$ as a function of humidity level. This plot reveals the Langmuir type of adsorptiondesorption isotherms.

\section{Conclusion}

A few milligrams of ammonium metavanadate powders were calcined in pure hydrogen atmosphere at temperature of $100,150,200,250,300$ and $350{ }^{\circ} \mathrm{C}$. The samples were characterized by TGA/DSC, XRD, TEM, Raman spectroscopy, FTIR,BET, VSM and XPS/EDS. All these characterization methods lead us to conclude that the progression from $\mathrm{NH}_{4} \mathrm{VO}_{3}$ to $\mathrm{V}_{2} \mathrm{O}_{5}$ is as follows: $\mathrm{NH}_{4} \mathrm{VO}_{3} \rightarrow \mathrm{VO}_{2}+\mathrm{V}_{2} \mathrm{O}_{5}\left(150-200^{\circ} \mathrm{C}\right) \rightarrow \mathrm{V}_{6} \mathrm{O}_{13}\left(300^{\circ} \mathrm{C}\right) \rightarrow \mathrm{V}_{2} \mathrm{O}_{5}$ (above $325^{\circ} \mathrm{C}$ ). At no temperature does one find a single phase; each temperature of calcinations will have a major and a minor phase or a number minor phases. The total surface 
area appears to increase with a decreasing rate as the temperature of calcinations is increased. A phase diagram based on XRD and Raman has been constructed for $\mathrm{VO}_{2}, \mathrm{~V}_{6} \mathrm{O}_{13}$ and $\mathrm{V}_{2} \mathrm{O}_{5}$. XPS/EDS analysis agrees with this phase diagram. It is also found that VSM confirms the order of $\mathrm{VO}_{2} \rightarrow \mathrm{V}_{6} \mathrm{O}_{13} \rightarrow \mathrm{V}_{2} \mathrm{O}_{5}$ transitions as temperatures of annealing are elevated.

\section{Acknowledgements}

Support from the India-Brazil-South Africa trilateral cooperation under the National Research Foundation (NRF) grant number HGER24X is acknowledged.

\section{References}

[1] P. S. Matsumoto, Trends in Ionization Energy of Transition-Metal Elements, J. Chem. Education, Vol. 82, No. 11, 2005.

[2] X. Chen, X. Wang, Z. Wang, J. Wan, J. Liu, Y. Qian, An ethylene glycol reduction approach to metastable $\mathrm{VO}_{2}$ nanowire arrays, Nanotech. 15 (2004) 1685-1687.

[3] M. Imada, A. Fujimori, Y. Tokura, Metal-insulator transitions, Rev. of Modern Phy. 70, No.4 1039-1263 (1998).

[4] N.F. Mott, Metal-insulator Transition, Rev. Modern Phys. 40 (4) (1968) 677.

[5] D. Adler, Mechanisms for Metal-Nonmetal Transitions in Transitions-Metal Oxides and Surfides, Rev. Modern Phys. 40 (4) (1968) 714-736.

[6] F.J. Morin, Oxides which show a metal-insulator-transition at Neel temperature, Phys. Rev. Lett. 3, (1959) 34.

[7] J.B. Goodenough, The two components of Crystallographic transition in $\mathrm{VO}_{2}$, J. Solid State Chem. 3, 490-500 (1971). 
[8] S. Shin, S. Suga, M. Tanuguchi, M. Fijisawa, H. Kansaki, A. Fujimori, H. Damon, Y. Ueda, K. Kosuge, S. Kachi, Vacuum-ultraviolet reflectance and photoemission study of the metal - insulator phase transitions in $\mathrm{VO}_{2}, \mathrm{~V}_{6} \mathrm{O}_{13}$, and $\mathrm{V}_{2} \mathrm{O}_{3}$, Phys. Rev. B 41, 4993-5009 (1990).

[9] J.M. Reyes, J.R. Marko, M. Sayer, Hysteresis in the Semiconductor-Metal Transition of Cr-doped $\mathrm{VO}_{2}$, Solid State Comm., Vol. 13 1953-1957 (1973).

[10] D. Paquet, P. Leroux-Hugon, Electron correlations and electron-lattice interactions in themetal-insulator, ferroelastic transition in $\mathrm{VO}_{2}$ : A thermodynamical study, Phys. Rev. B22, 5284-5301 (1980).

[11] N.F. Mott, R. Peierls, Discussion of the paper by de Boer and Verwey Proc. Phys. Soc. London, Ser. A. 49, 72 (1937).

[12] A. I. Buzdin, L N. Bulaevskii, P. N. Lebedev, Spin-Peierls transition in quasi-one dimensional crystals, Physics Institute, Academy of Sciences of the USSR, Moscow Usp Fiz Nauk, 131, 495-510 (July 1980).

[13] G.I. Petrov, V.V. Yakovlev, Raman microscopy analysis of phase transformation mechanisms in vanadium dioxide, App. Phy. Lett. Vol. 81. No. 6 (2002).

[14] S.-Y. Li, G. A. Niklasson, and C. G. Granqvist, Nanothermochromics: Calculations for $\mathrm{VO}_{2}$ nanoparticles in dielectric hosts show much improved luminous transmittance and solar energy transmittance modulation, J. Appl. Phys. 108, 063525 (2010).

[15] R. Lopez, R. F. Haglund, Jr., L. C. Feldman, L. A. Boatner, T. E. Hayness, Optical nonlinearities in $\mathrm{VO}_{2}$ nanoparticles and thin films, App. Phy. Lett 85, (2004).

[16] S. Lysenko, A. Rua, F. Fernandez, H. Liu, Vanadium dioxide based plasmonic modulators, J. Appl. Phys. 105, 043502 (2009)

[17] J. Cao, W. Fan, J-Q. Wu, Strain and temperature dependence of the insulating phases of $\mathrm{VO}_{2}$ near the metal-insulator transition, Phy. Rev. B 85, 020101(R) (2012) 
[18] Z. Lu, C-G.Lia,Y. Yin, Synthesis and thermochromic properties of vanadium dioxide colloidal Particles, J. Mater. Chem., 2011, 21, 14776-14782

[19] E .U. Donev, J. I. Ziegler, R. F Haglund Jr., L. C. Feldman, Size effects in the structural phase transition of $\mathrm{VO}_{2}$ nanoparticles studied by surface-enhanced Raman scattering, J. Opt. A: Pure Appl. Opt. 11(2009) 125002 (8pp).

[20] A. C. Jones, S. Berweger, J. Wei, D. Cobden, M. B. Raschke, Nano-optical investigations of the metal-insulator phase behaviour of individual $\mathrm{VO}_{2}$ microcrystals, Nano Lett. 2010, 10, 1574-1581.

[21] M. Maaza, O. Nemraoui, C. Sella, A. C. Beye, B. Baruch-Barak, Thermal induced tenability of surface plasmon resonance in $\mathrm{Au}-\mathrm{VO}_{2}$ nano-photonics, Optics Comm. 254 (2005) 188-195.

[22] A. Pergrament, G. Stefanovich, O. Berezina, D. Kirienko, Electrical conductivity of tungsten doped vanadium dioxide obtained by the sol-gel technique, Thin Solid Films 572$576(2013)$

[23] Y. Gao, H. Luo, Z. Zhang, L. Kang, Z. Chen, J. Du, M. Kanehira, C. Cao, Nanoceramic $\mathrm{VO}_{2}$ thermochromic smart glass: A review on progress in solution processing, Nano Energy (2012) 1, 221-246.

[24] W. Burkhardt, T. Christmann, B.K. Meyer, W. Niessner, D. Schalch, A. Scharmann , Wand F-doped $\mathrm{VO}_{2}$ films studied by photoelectron spectrometry, Thin Sol. Films. 345 (1999) $229-235$.

[25] O. Y. Berezina, A. A. Velichko, L.A. Lugovskaya, A.L. Pergament, G.B. Stefanovich, D.V. Artyukhin, A. N. Strelko, Properties of Tungsten-Doped Vanadium Oxide Films, Tech. Phys. Lett. (2007) Vol. 33, No. 7, pp. 552-555.

[26] R. Binions, G. Hyett, C. Piccirillo, I. P. Parkin, Doped and Undoped vanadium dioxide thin films prepared by atmospheric pressure chemical vapour deposition from vanadyl 
acetylacetonate and tungsten hexachloride: the effects of thickness and crystallographic orientation on thermocromic properties, J. Mat. Chem. 17, 4652-4660 (2007)

[27] E. Strelcov, Y. Lilach, A. Kolmakov, Gas Sensor Based on Metal-Insulator Transition in $\mathrm{VO}_{2}$ Nanowire Thermistor, Nano Letters 2009, Vol. 9, No. 6, 2322-23269

[28] C.G. Granqvist, Electrochromic tungsten oxide films: Review of progress 1993- 1998, Solar Energy Materials \& Solar Cells 60 (2000) 201- 262

[29] J. Livage_, D. Ganguli, Sol-gel electrochromic coatings and devices: A review, Solar Energy Materials \& Solar Cells 68 (2001) 365-381

[30] J. Huotari, A. L. Spetz1, J. Lappalainen, Gas Sensing Properties of Pulsed Laser Deposited Vanadium Oxide Thin Films, The 14th International Meeting on Chemical Sensors, IMCS 2012.

[31] M.C. Rao, Vanadium Pentoxide Cathode Material for Fabrication of All Solid State Lithium-Ion Batteries - A Case Study, Res. J. Recent Sci. Vol. 2(3), 67-73, March (2013)

[32] P. Kiria, G. Hyettb, R. Binions, Solid state thermochromic materials, Adv. Mat. Lett. 2010, 1(2), 86-105.

[33] H. Bai, M. Berkahn, M.B. Cortie, 31 Annual Condensed Matter and Materials 2007

[34] L. Chen, Ch. Huang, G. Xu, L. Miao, J. Shi, J. Zhou, X. Xiao, Synthesis of Thermochromic W-Doped $\mathrm{VO}_{2}(\mathrm{M} / \mathrm{R})$ Nanopowders by a Simple Solution-Based Process, J. Nanomaterials, (2012) 1-8, doi:10.1155/2012/491051

[35] M. Taniguchi, T.R. Ingraham, Mechanism of thermal decomposition of Ammonium metavadate, Canadian Journal of Chemistry, (1964) 42(11) 2467-2473

[36] B.W. Mwakikunga, E. Sidras-Haddad, M. Maaza, First synthesis of vanadium dioxide by ultrasonic nebula-spray pyrolysis, Optical Materials 29 (2007) 481-487 
[37] B.W. Mwakikunga, M. Maaza, K.T. Hillie, C.J. Arendse, T. Malwela, E. SiderasHaddad, From phonon confinement to phonon splitting in flat single nanostructures: A case of $\mathrm{VO}_{2} @ \mathrm{~V}_{2} \mathrm{O}_{5}$ core-shell nano-ribbons, Vibrational Spectroscopy 2025 (2012).

[38] X. Wua, Y. Taoa, L. Donga, Z. Wangb, Z. Hua, Preparation of $\mathrm{VO}_{2}$ nanowire and their characterization, Mat. Res. Bullet. 40 (2005) 315-321

[39] U.V. Sacken, J.R. Dahn, TGA/MS Studies of the thermal decomposition of $\mathrm{NH}_{4} \mathrm{VO}_{3}, \mathrm{~J}$. Power Sources, 26 (1989) 461-465

[40] M.E. Brown, B.V. Stewart, The thermal decomposition of ammonium metavanadate, J. Thermal Anal. Vol. 2 (1970) 287-299

[41] J. Twu, C-F. Shih, T-H, Guo, K-H, Chen, Raman spectroscopic studies of the thermal decomposition mechanism of ammonium metavanadate, J. Mater. Chem., 19977 (11) 22732277

[42] C. Julien, G. A. Nazri, and O. Bergstrom, Raman Scattering Studies of Microcrystalline V6O13, Phys. Stat. Solidi B 201, 319-326 (1997)

[43] D. Vernardou, M. Apostolopoulou, D. Louloudakis, E. Spanakis, N. Katsarakis, E. Koudoumas, J. MacGrath, M.E Pemble, Electrochemical properties of Opal- $\mathrm{V}_{6} \mathrm{O}_{13}$ composites, J. Alloy and Compound 2014 (582) 621-626.

[44] K. Virkler, I. K. Lednev, Raman spectroscopic signature of semen and its potential application to forensic body fluid identification, Forensic Science International 193 (2009) $56-62$

[45] I.L. Botto, M.B. Vassallo, E.J. Baran, G. Minelli, IR spectra of $\mathrm{VO}_{2}$ and $\mathrm{V}_{2} \mathrm{O}_{5}$, Matt. Chem. and Phy. 50 (1997) 267-270. 
[46] S. Brunauer, P. H. Emmett, E. Teller, Adsorption of Gases in Multimolecular Layers, J. Am. Chem. Soc., 1938, 60 (2), pp 309-319

[47] R. F. Karlak, D. S. Burnett, Quantitative phase analysis by X-ray diffraction, Analytical Chem. 38 (1966) 1741-1745

[48] A.A. Akande , K. E. Rammutla, T. Moyo, N. S.E. Osman, Steven S. Nkosi, C.J. Jafta, Bonex W. Mwakikunga, Magnetism variations and susceptibility hysteresis at the metalinsulator phase transition temperature of $\mathrm{VO}_{2}$ in a composite film containing vanadium and tungsten oxides, J Magn. Magn. Mater. 375 (2015) 1-9

[49] ] J. Nogués, J. Sort, V. Langlais, V. Skumryev, S. Surinack, J.S. Munoz, M.D. Baró, Exchange bias in nanostructures, Phys. Rep. 422 (2005) 65-117

[50] K. Mbela, T. Moyo, J.Z. Msomi, M. Ozturk, N. Akdogan, Synthesis and magnetic properties of $\mathrm{Mg}_{0.2} \mathrm{Cr}_{1.8-\mathrm{x}} \mathrm{Fe}_{\mathrm{x}} \mathrm{O}_{3}$, J. Magn. Magn. Mater. 330 (2013) 159-162

[51] B. W. Mwakikunga, S. Motshekga, L. Sikhwivhilu, Mathew Moodley, M. Scriba, Gerald Malgas, A. Simo, B. Sone, M. Maaza, Suprakas Sinha Ray, A classification and ranking system on the $\mathrm{H} 2$ gas sensing capabilities of nanomaterials based on proposed coefficients of sensor performance and sensor efficiency equations, Sensors \& Actuators B 184 (2013) 170178

[52] A. Simo, B. Mwakikunga, B. T. Sone, B. Julies, R. Madjoe, M. Maaza, VO2 nanostructures based chemiresistors for low power energy consumption hydrogen sensing, Int. J. of Hydrogen Energy 39 (2014) 8147 - 8157 


\section{Highlights}

- Validated the theoretical mass losses at each temperature of $\mathrm{NH}_{4} \mathrm{VO}_{3}$ with TGA

- Confirmed mechanisms of formation of various stoichiometries of $\mathrm{VO}_{\mathrm{x}}$ from $\mathrm{NH}_{4} \mathrm{VO}_{3}$

- Determined the evolution of $\mathrm{VO}_{2}, \mathrm{~V}_{6} \mathrm{O}_{13}$ and $\mathrm{V}_{2} \mathrm{O}_{5}$ with temperature.

- Phase diagram of $\mathrm{VO}_{2}, \mathrm{~V}_{6} \mathrm{O}_{13}$ and $\mathrm{V}_{2} \mathrm{O}_{5}$ by VSM, XPS/EDS, XRD and Raman spectra

- Comparative response of $\mathrm{VO}_{2}, \mathrm{~V}_{6} \mathrm{O}_{13}$ and $\mathrm{V}_{2} \mathrm{O}_{5}$ to humidity 


\section{APPENDIX A SUPPLEMENTARY DATA}

\section{SM1}

A $4.726 \mathrm{mg}$ of $\mathrm{NH}_{4} \mathrm{VO}_{3}$ powder was introduced into TGA system, the molar mass of $\mathrm{NH}_{4} \mathrm{VO}_{3}$ is $116.98 \mathrm{~g}$ and the number of mole based on the weight of $\mathrm{NH}_{4} \mathrm{VO}_{3}$ is calculated as $4.04 \times 10^{-5} \mathrm{~mol}$. The decomposition mechanisms $(1-5)$ in the full manuscripts were considered with mechanism (3) found to be an applicable mechanism in our case.

$4 \mathrm{NH}_{4} \mathrm{VO}_{3} \rightarrow\left(\mathrm{NH}_{4}\right)_{2} \mathrm{~V}_{4} \mathrm{O}_{11}+2 \mathrm{NH}_{3}(g)+\mathrm{H}_{2} \mathrm{O}(\mathrm{g})$

Molar mass of other components $(\mathrm{NH} 4)_{2} \mathrm{~V}_{4} \mathrm{O}_{11}, \mathrm{NH}_{3}$ and $\mathrm{H}_{2} \mathrm{O}$ were estimated as $415.834 \mathrm{~g}$, $17.0307 \mathrm{~g}$ and $18.0148 \mathrm{~g}$ respectively.

The following calculations were performed as follows,

$$
\begin{array}{ll}
\text { Mass of }(\mathrm{NH} 4)_{2} \mathrm{~V}_{4} \mathrm{O}_{11}=\left(4.04 \times 10^{-5} / 4\right) \times 415.834 & =4.199 \times 10-^{3} \mathrm{~g} \\
\text { Mass of } \mathrm{NH}_{3} & =\left(4.04 \times 10^{-5} / 2\right) \times 17.0307=3.44 \times 10^{-4} \mathrm{~g} \\
\text { Mass of } \mathrm{H}_{2} \mathrm{O} & =\left(4.04 \times 10^{-5} / 4\right) \times 18.0148=1.819 \times 10^{-4} \mathrm{~g}
\end{array}
$$

Total mass of all components in this mechanism is found to be $4.7249 \times 10^{-3} \mathrm{~g}$ which validates mechanism 3 as the process involved in our experiment.

\section{SM2}

TGA residual mass of $\mathrm{V}_{6} \mathrm{O}_{13}$ powder (fig. $1(\mathrm{c})$ ) at $147.9{ }^{0} \mathrm{C}$ is recorded as $4.9702 \mathrm{mg}$ and its molar mass is found to be $513.639 \mathrm{~g}$. The number of mole is calculated as expressed below.

$$
\text { Number of mole }=4.9702 \times 10^{-3} / 513.639=9.676 \times 10^{-6} \mathrm{~mol} \text {. }
$$

Mechanism (6) in the full manuscript was proposed.

$$
2 \mathrm{~V}_{6} \mathrm{O}_{13} \rightarrow 12 \mathrm{VO}_{2}+\mathrm{O}_{2}
$$

Molar mass of other components $\mathrm{VO}_{2}$ and $\mathrm{O}_{2}$ were estimated as $82.94 \mathrm{~g}$ and $31.998 \mathrm{~g}$ respectively.

The following calculations were performed as follows,

Mass of $\mathrm{VO}_{2}=9.676 \times 10^{-6} \times 6 \times 82.94=4.818 \times 10^{-3} \mathrm{~g}$

Mass of $\mathrm{O}_{2}=9.676 \times 10^{-6} \times 31.998=1.548 \times 10^{-4} \mathrm{~g}$

Total mass of all components is found to be $4.972 \times 10^{-3} \mathrm{~g}$ which is also correspond to the mass at $147.9{ }^{0} \mathrm{C}$.

The $\%$ mass loss (experimental) is calculated by subtracting the mass at $147.9^{0} \mathrm{C}$ from the original mass introduce to the TGA system as express below. 
$\%$ mass loss $($ experimental $)=(5.093-4.9702) 10^{-3} / 4.9702 \times 10^{-3} \times 100 \%$

$$
=2.53 \%
$$

The \% mass loss (theoretical) is calculated by subtracting the mass of VO2 based on mechanism (6) from the total mass as expressed below.

$\%$ mass loss $($ theoretical $)=(4.972-4.818) 10^{-3} / 4.818 \times 10^{-3} \times 100 \%$

$$
=3.09 \%
$$

This show that the experimental value is close to theoretical, and that the conversion from $\mathrm{V}_{6} \mathrm{O}_{13}$ to $\mathrm{VO}_{2}$ is possible around $147.9^{0} \mathrm{C}$.

SM3

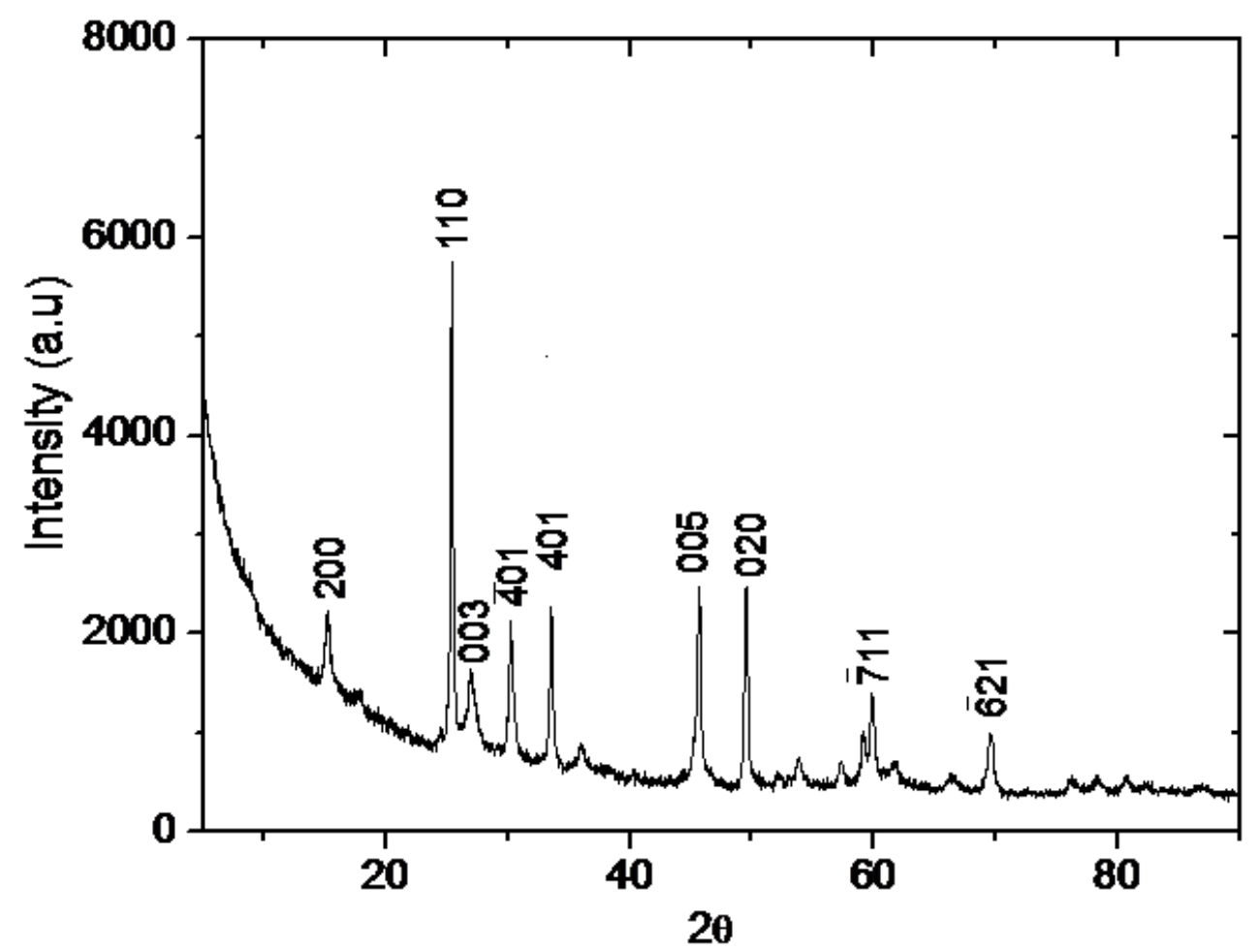

XRD pattern of the sample prepared at $400{ }^{\circ} \mathrm{C}$ 
SM4

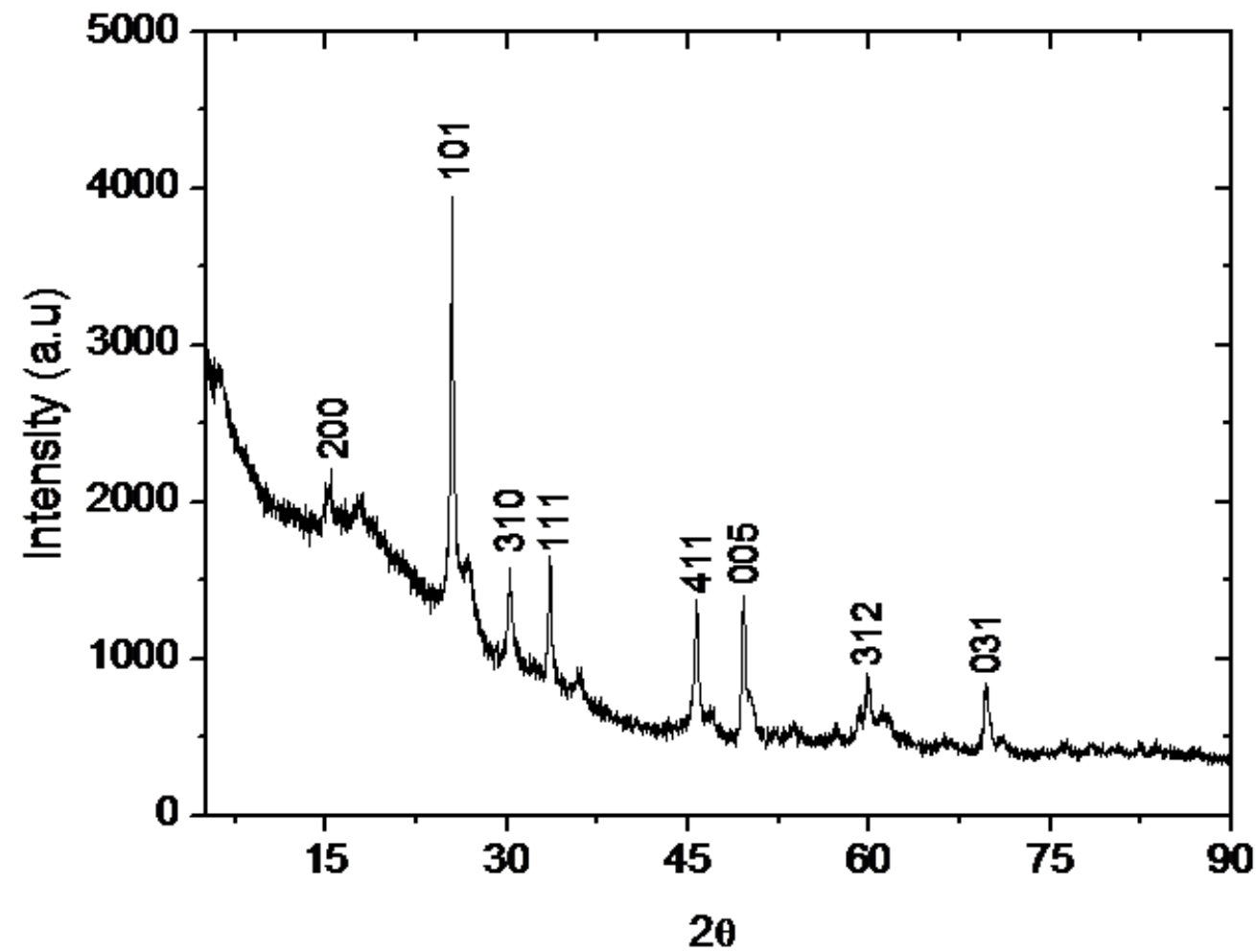

XRD pattern of the sample prepared at $500{ }^{\circ} \mathrm{C}$ 
SM5

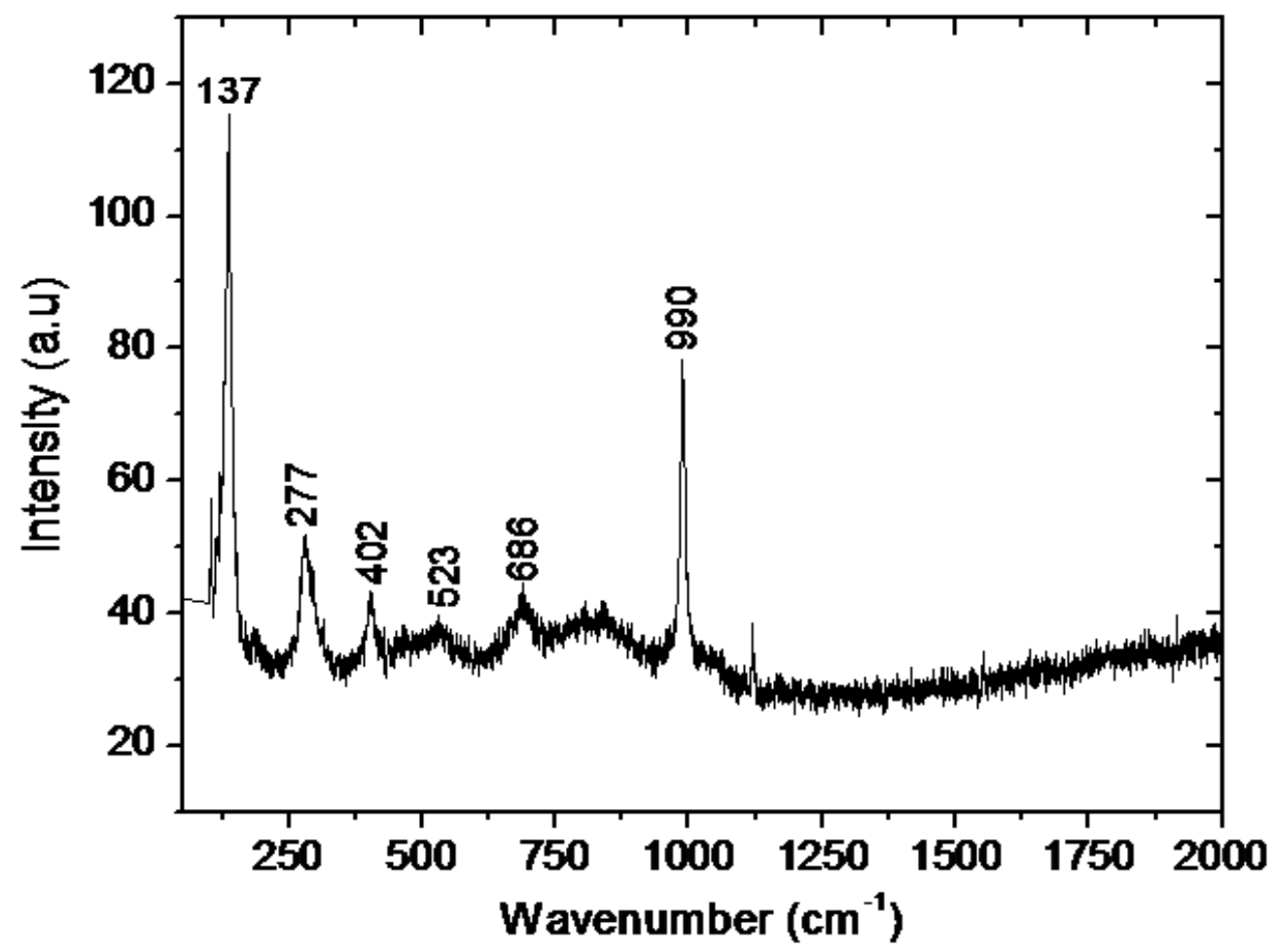

Raman spectrum of the sample prepared at $400{ }^{0} \mathrm{C}$ 
SM6

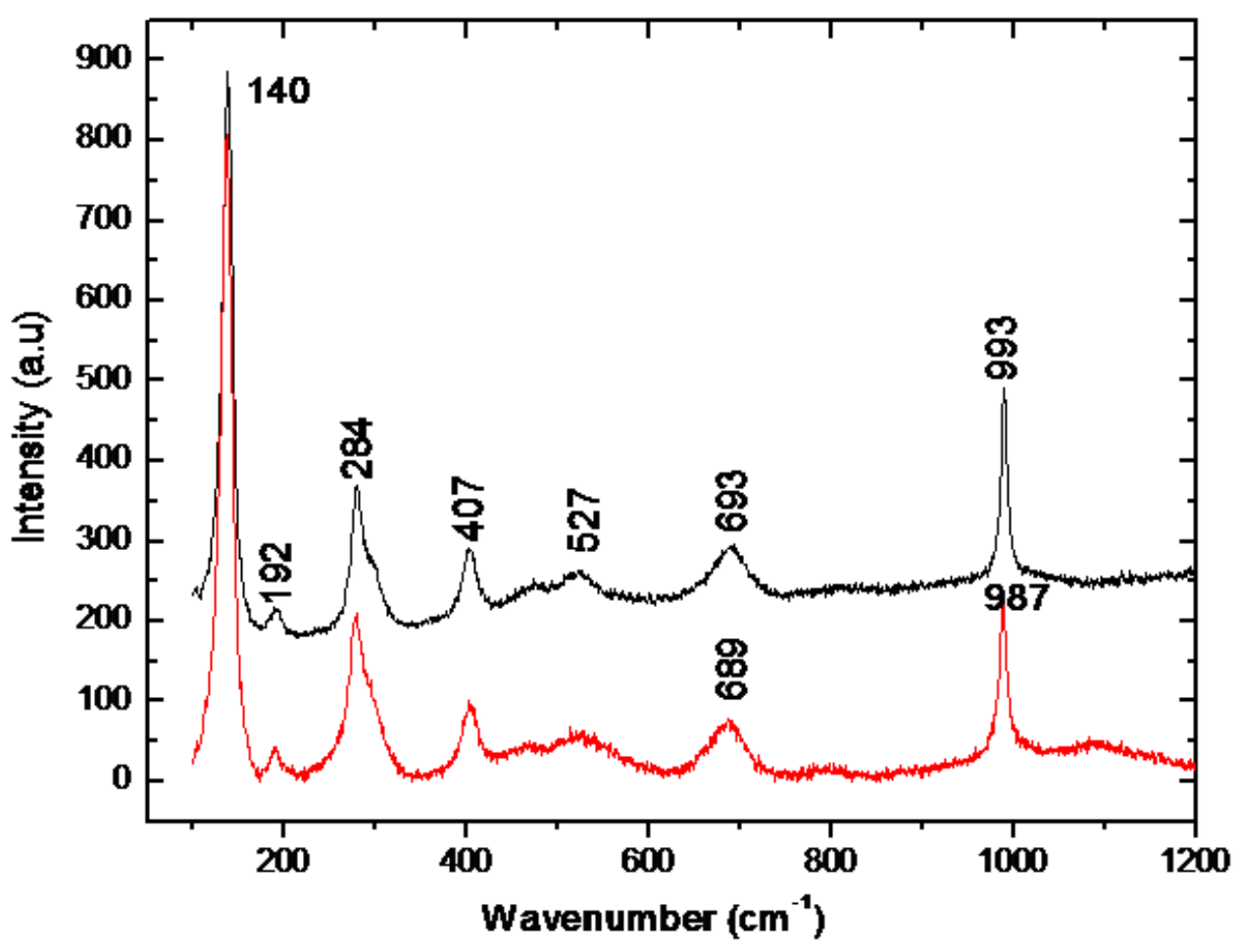

Black line is Raman spectrum of the sample prepared at $500{ }^{0} \mathrm{C}$. Red line spectra is for $\mathrm{NH}_{4} \mathrm{VO}_{3}$ solution $\left(\mathrm{V}^{5+}\right.$ state) drop cast on the corning glass substrates, similar vibration modes were achieved except $6 \mathrm{~cm}^{-1}$ blue shift at higher frequency modes of 993 and $987 \mathrm{~cm}^{-}$ ${ }^{1}$. This shows that $\mathrm{NH}_{4} \mathrm{VO}_{3}$ in the liquid state could be $\mathrm{V}_{2} \mathrm{O}_{5}$ in terms of its molecules vibration. 